ARTICLE

\title{
High-efficiency direct methane conversion to oxygenates on a cerium dioxide nanowires supported rhodium single-atom catalyst
}

\author{
Shuxing Bai ${ }^{1,6}$, Fangfang Liu' ${ }^{2,6}$, Bolong Huang (10 ${ }^{3,6}$, Fan $\mathrm{Li}^{4}$, Haiping Lin (1) ${ }^{2}$, Tong Wu ${ }^{3}$, Mingzi Sun (1) ${ }^{3}$, \\ Jianbo Wu ${ }^{4,5 凶}$, Qi Shao ${ }^{1}$, Yong Xu (iD ${ }^{2 \otimes} \&$ Xiaoqing Huang ${ }^{1 凶}$
}

Direct methane conversion (DMC) to high value-added products is of significant importance for the effective utilization of $\mathrm{CH}_{4}$ to combat the energy crisis. However, there are ongoing challenges in $\mathrm{DMC}$ associated with the selective $\mathrm{C}-\mathrm{H}$ activation of $\mathrm{CH}_{4}$. The quest for highefficiency catalysts for this process is limited by the current drawbacks including poor activity and low selectivity. Here we show a cerium dioxide $\left(\mathrm{CeO}_{2}\right)$ nanowires supported rhodium (Rh) single-atom ( $\mathrm{SAs} \mathrm{Rh}-\mathrm{CeO}_{2} \mathrm{NWs}$ ) that can serve as a high-efficiency catalyst for DMC to oxygenates (i.e., $\mathrm{CH}_{3} \mathrm{OH}$ and $\mathrm{CH}_{3} \mathrm{OOH}$ ) under mild conditions. Compared to $\mathrm{Rh} / \mathrm{CeO}_{2}$ nanowires (Rh clusters) prepared by a conventional wet-impregnation method, $\mathrm{CeO}_{2}$ nanowires supported Rh single-atom exhibits 6.5 times higher of the oxygenates yield (1231.7 vs. $189.4 \mathrm{mmol}_{\mathrm{Rh}}{ }^{-1} \mathrm{~h}^{-1}$ ), which largely outperforms that of the reported catalysts in the same class. This work demonstrates a highly efficient DMC process and promotes the research on Rh single-atom catalysts in heterogeneous catalysis.

\footnotetext{
${ }^{1}$ College of Chemistry, Chemical Engineering and Materials Science, Soochow University, Jiangsu 215123, China. ${ }^{2}$ Institute of Functional Nano\&Soft Materials (FUNSOM), Jiangsu Key Laboratory for Carbon-Based Functional Materials \& Devices, Soochow University, Jiangsu 215123, China. ${ }^{3}$ Department of Applied Biology and Chemical Technology, The Hong Kong Polytechnic University, Hung Hom, Kowloon, Hong Kong SAR, China. ${ }^{4}$ State Key Laboratory of Metal Matrix Composites, School of Materials Science and Engineering, Shanghai Jiao Tong University, Shanghai 200240, China. ${ }^{5}$ Center of Hydrogen Science, Shanghai Jiao Tong University, Shanghai 200240, China. ${ }^{6}$ These authors contributed equally: Shuxing Bai, Fangfang Liu, Bolong Huang.

凶email: jianbowu@sjtu.edu.cn; xuy@suda.edu.cn; hxq006@suda.edu.cn
} 
M ethane $\left(\mathrm{CH}_{4}\right)$ is in fact among the most important and attractive feedstocks for producing methanol $\left(\mathrm{CH}_{3} \mathrm{OH}\right)$ and other high value-added products in the chemical industry ${ }^{1,2}$. In the traditional processes, $\mathrm{CH}_{4}$ is converted into $\mathrm{CH}_{3} \mathrm{OH}$ indirectly via the formation of syngas $\left(\mathrm{H}_{2}\right.$ and $\left.\mathrm{CO}\right)$, which is an energy-hungry process that needs to be performed under high temperature ${ }^{3,4}$. Therefore, the direct $\mathrm{CH}_{4}$ conversion (DMC) to $\mathrm{CH}_{3} \mathrm{OH}$, which is regarded as a "dream reaction" in chemical industry, has been the subject of intensive study for decades ${ }^{5-7}$. For instance, Periana et al. reported that $\mathrm{CH}_{4}$ can be converted to $\mathrm{CH}_{3} \mathrm{OH}$ by mercuric ions in the presence of concentrated sulfuric acid ${ }^{8}$. Sushkevich et al. ${ }^{9}$ synthesized a coppercontaining zeolite catalyst and used it for the conversion of $\mathrm{CH}_{4}$ to $\mathrm{CH}_{3} \mathrm{OH}$ with high selectivity $(\sim 97 \%)$ at $200^{\circ} \mathrm{C}$. More recently, Agarwal et al. used colloidal gold-palladium nanoparticles ( $\mathrm{Au}-\mathrm{Pd} \mathrm{NPs}$ ) to catalyze the DMC to $\mathrm{CH}_{3} \mathrm{OH}$, methylhydroperoxide $\left(\mathrm{CH}_{3} \mathrm{OOH}\right)$, and formic acid $(\mathrm{HCOOH})$ in the presence of hydrogen peroxide $\left(\mathrm{H}_{2} \mathrm{O}_{2}\right)$ and oxygen $\left(\mathrm{O}_{2}\right)^{10}$. The yield of these primary oxygenates product reaches $\sim 53.6 \mathrm{~mol}$ $\mathrm{kg}_{\text {cat }}{ }^{-1} \mathrm{~h}^{-1}$ at a selectivity of $88.0 \%$ at $50^{\circ} \mathrm{C}^{10}$. Shan et al. ${ }^{2}$ reported that mononuclear rhodium species on ZSM-5 can catalyze DMC to $\mathrm{CH}_{3} \mathrm{OH}$ and acetic acid $\left(\mathrm{CH}_{3} \mathrm{COOH}\right)$ using $\mathrm{O}_{2}$ and carbon monoxide $(\mathrm{CO})$ with the total yield of oxygenates $\sim 10 \mathrm{mmol} \mathrm{g}_{\text {cat. }}{ }^{-1} \mathrm{~h}^{-1}$ and the selectivity of $\mathrm{CO}_{2} \sim 15 \%{ }^{2}$. Despite the tremendous progress on the development of catalysts and technologies, DMC to oxygenates is extremely challenging because the selective activation of $\mathrm{C}-\mathrm{H}$ bonds in $\mathrm{CH}_{4}$ under mild conditions is a tough issue. It is thus highly desired to develop active and selective catalysts for the DMC to oxygenates.

Noble metals-based single-atom catalysts (SACs) have emerged as a new frontier in heterogenous catalysis because of large ratio of surface atoms, low-coordination environment of metal centers, and strong metal-support interactions ${ }^{11-13}$. They have been widely studied in diverse processes with superior catalytic performance, including $\mathrm{CO}$ oxidation, $\mathrm{CH}_{4}$ conversion, oxygen reduction, water gas shift reaction, and so on ${ }^{14-16}$. Recent investigations show that SACs can be used as highly active and selective catalysts for alkynes hydrogenation, in which the isolated active sites are geometrically in favor of the selective hydrogenation of alkynes ${ }^{17-20}$. For instance, Kyriakou et al. ${ }^{17}$ demonstrated that the isolated Pd atoms in a Cu surface can be used as a highly selective catalyst for the hydrogenation of styrene and acetylene as compared with pure $\mathrm{Cu}$ or Pd metal. Yan et al. ${ }^{18}$ claimed that Pd SAs can selectively catalyze butadiene to butene because of the mono- $\pi$-adsorption mode and the steric effect induced by butadiene adsorption on the isolated Pd atoms. Typical for $\mathrm{CH}_{4}$ conversion, Tang et al. ${ }^{15}$ reported that the singlesite $\mathrm{Rh}_{1} \mathrm{O}_{5}$ anchored in microporous aluminosilicates (ZSM-5) can catalyze the DMC to $\mathrm{CH}_{3} \mathrm{COOH}$ and $\mathrm{CH}_{3} \mathrm{OH}$ in the presence of $\mathrm{CH}_{4}, \mathrm{CO}$, and $\mathrm{O}_{2}$ at $\leq 150^{\circ} \mathrm{C}$. It is found that the single-site $\mathrm{Rh}_{1} \mathrm{O}_{5}$ plays the role of the active site for DMC, while the rhodium oxide NPs on ZSM-5 are even not active for this transformation ${ }^{15}$. Kwon et al. ${ }^{16}$ demonstrated that $\mathrm{Rh} \mathrm{SA}$ on $\mathrm{ZrO}_{2}$ can be used for the DMC to $\mathrm{CH}_{3} \mathrm{OOH}$ and $\mathrm{CH}_{3} \mathrm{OH}$ in $\mathrm{H}_{2} \mathrm{O}_{2}$ solution at $70^{\circ} \mathrm{C}$. However, the selectivity of oxygenates from Rh SA on $\mathrm{ZrO}_{2}$ is $\sim 70 \%$ due to the different decomposition rate of $\mathrm{H}_{2} \mathrm{O}_{2}$ and $\mathrm{CH}_{3} \mathrm{OOH}$ on $\mathrm{ZrO}_{2}{ }^{16}$. Inspired by these reports, we believe that the Rh SACs can be used as promising catalysts for DMC, and the selectivity of oxygenates may be strongly related to the support for anchoring Rh SA.

Herein, we synthesized Rh-based SACs on $\mathrm{CeO}_{2}$ nanowires (SAs $\mathrm{Rh}-\mathrm{CeO}_{2} \mathrm{NWs}$ ) via a simple hydrothermal process. The results show that $\mathrm{SAs} \mathrm{Rh}-\mathrm{CeO}_{2}$ NWs can be used as a highly efficient catalyst for DMC to oxygenates in the presence of $\mathrm{H}_{2} \mathrm{O}_{2}$ at $50{ }^{\circ} \mathrm{C}$. Different from the previous work, our work reveals that the support for anchoring Rh SAs (i.e., $\mathrm{CeO}_{2} \mathrm{NWs}$ ) is involved in the formation of radicals, which can further enhance the activity of DMC. The total yield and selectivity of oxygenates reach $\sim 1231.7 \mathrm{mmol} \mathrm{g}_{\mathrm{Rh}}{ }^{-1} \mathrm{~h}^{-1}$ and $93.9 \%$, respectively. To the best of our knowledge, the current DMC performance outperforms the reported catalysts in literatures. In situ characterizations and theoretical calculations show that $\mathrm{CeO}_{2} \mathrm{NWs}$ play a vital role in the formation of $\cdot \mathrm{OOH}$ and $\cdot \mathrm{OH}$ radicals. SAs $\mathrm{Rh}-\mathrm{CeO}_{2} \mathrm{NWs}$ can selectively activate $\mathrm{CH}_{4}$ to $\cdot \mathrm{CH}_{3}$, which further combines with . $\mathrm{OOH}$ and $\cdot \mathrm{OH}$ radicals to form $\mathrm{CH}_{3} \mathrm{OH}$ and $\mathrm{CH}_{3} \mathrm{OOH}$, respectively. By contrast, the $\mathrm{Rh} / \mathrm{CeO}_{2}$ NWs tend to overoxidize $\mathrm{CH}_{4}$ to $\mathrm{CO}_{\mathrm{x}}$ species with the assistance of $\cdot \mathrm{OH}$, leading to a low oxygenates' yield and selectivity $\left(189.4 \mathrm{mmol} \mathrm{g}_{\mathrm{Rh}}{ }^{-1} \mathrm{~h}^{-1}\right.$ and $56.4 \%)$

\section{Results}

Preparation and morphology characterization. $\mathrm{CeO}_{2} \mathrm{NWs}$ were prepared via a simple hydrothermal process by adding cerium chloride $\left(\mathrm{CeCl}_{3}\right)$, sodium oleate, deionized water $\left(\mathrm{H}_{2} \mathrm{O}\right)$, and $n$ butylamine into a stainless reactor. The synthetic method of SAs Rh- $-\mathrm{CeO}_{2} \mathrm{NWs}$ was the same as that of $\mathrm{CeO}_{2} \mathrm{NWs}$, except for adding additional sodium hexachlororhodate $\left(\mathrm{Na}_{3} \mathrm{RhCl}_{6}\right) . \mathrm{Rh} /$ $\mathrm{CeO}_{2} \mathrm{NWs}$ and $\mathrm{Rh} / \mathrm{CeO}_{2}$-com were prepared by impregnating $\mathrm{Na}_{3} \mathrm{RhCl}_{6}$ on the as-prepared $\mathrm{CeO}_{2} \mathrm{NWs}$ and commercial $\mathrm{CeO}_{2}$ via a conventional wet-impregnation method. The physicochemical properties are listed in Supplementary Table 1. Transmission electron microscopy (TEM) image shows that uniform $\mathrm{CeO}_{2} \mathrm{NWs}$ with a diameter and length of $\sim 6.2 \mathrm{~nm}$ and $\sim 260 \mathrm{~nm}$ are obtained (Supplementary Fig. 1). No Rh nanoparticles are observed in TEM image, indicating that $\mathrm{Rh}$ atoms are well dispersed in SAs $\mathrm{Rh}$ $\mathrm{CeO}_{2}$ NWs (Fig. 1a). The aberration-corrected high-angle annular dark-field scanning transmission electron microscopy (ACHAADF/STEM) image in temperature color of SAs $\mathrm{Rh}-\mathrm{CeO}_{2}$ NWs indicates $\mathrm{Rh}$ atoms are presented as SA state (Fig. 1b, c; Supplementary Fig. 2). By contrast, Rh clusters with the size of $\sim 1.5 \mathrm{~nm}$ appear in the AC-HAADF/STEM image in temperature color of $\mathrm{Rh} / \mathrm{CeO}_{2} \mathrm{NWs}$ (Fig. 1d, e; Supplementary Fig. 3). In X-ray diffraction (XRD) pattern of SAs Rh- $\mathrm{CeO}_{2} \mathrm{NWs}$, only the characteristic peaks of $\mathrm{CeO}_{2}$ at $2 \theta=28.5,33.1,47.5,56.3,69.4,76.7$, 79.1, and $88.4^{\circ}$ (PDF No. 43-1002) are observed (Supplementary Fig. 4), indicating that $\mathrm{Rh}$ atoms are highly dispersed on $\mathrm{CeO}_{2}$ NWs and commercial $\mathrm{CeO}_{2}$, despite the full wavelength at half maximum (FWHM) of the characteristic peaks corresponding to $\mathrm{CeO}_{2} \mathrm{NWs}$ is much broader than that of commercial $\mathrm{CeO}_{2}$ due to its small diameter of $\sim 6.2 \mathrm{~nm}^{21}$. It should be noted that the absence of peaks corresponding to Rh clusters in the XRD pattern of $\mathrm{Rh} / \mathrm{CeO}_{2}$ NWs might be attributed to the very small-sized $\mathrm{Rh}$ clusters and low content of $\mathrm{Rh}$ in the catalyst. X-ray photoelectron spectroscopy measurements were performed to characterize the chemical states of elements on the surface of $\mathrm{CeO}_{2} \mathrm{NWs}$, SAs Rh$\mathrm{CeO}_{2} \mathrm{NWs}, \mathrm{Rh} / \mathrm{CeO}_{2} \mathrm{NWs}$, and $\mathrm{Rh} / \mathrm{CeO}_{2}-\mathrm{com}$. As shown in Supplementary Fig. 5 , it is found that $\mathrm{Rh}$ are in their oxidation state $\left(\mathrm{Rh}^{3+}\right)$, while Ce consist of $\mathrm{Ce}^{4+}(881.8,888.3,897.6,900.3$, 907.2, and $916.0 \mathrm{eV})$ and $\mathrm{Ce}^{3+}(884.6 \text { and } 903.1 \mathrm{eV})^{22}$. The binding energy shifts of Rh in XPS spectra indicate that the different synergies among those catalysts. Compared with the $\mathrm{Rh} /$ $\mathrm{CeO}_{2}$-com $(308.9 \mathrm{eV})$ and $\mathrm{Rh} / \mathrm{CeO}_{2}$ NWs $(309.1 \mathrm{eV})$, $\mathrm{Rh} 3 \mathrm{~d} 5 / 2$ peak obviously shifts to $309.4 \mathrm{eV}$ in $\mathrm{SAs} \mathrm{Rh}-\mathrm{CeO}_{2} \mathrm{NWs}$, suggesting the existence of electron transfer from $\mathrm{Rh}$ to $\mathrm{CeO}_{2}$ in $\mathrm{SAs}$ Rh- $\mathrm{CeO}_{2}$ NWs (Supplementary Fig. 5a). On the other hand, detailed peak fittings demonstrate that the proportions of $\mathrm{Ce}^{3+}$ are different among these samples (Supplementary Fig. 5b). In particular, the proportion of $\mathrm{Ce}^{3+}$ in $\mathrm{Rh} / \mathrm{CeO}_{2}-\mathrm{com}$ is $12.4 \%$, which is much lower than that in $\mathrm{CeO}_{2}$ NWs (16.0\%), $\mathrm{Rh} / \mathrm{CeO}_{2} \mathrm{NWs}$ (16.5\%), and $\mathrm{SAs} \mathrm{Rh}-\mathrm{CeO}_{2}$ NWs (16.7\%). XPS results imply a much stronger synergy exists in $\mathrm{SAs} \mathrm{Rh}-\mathrm{CeO}_{2} \mathrm{NWs}$ in 

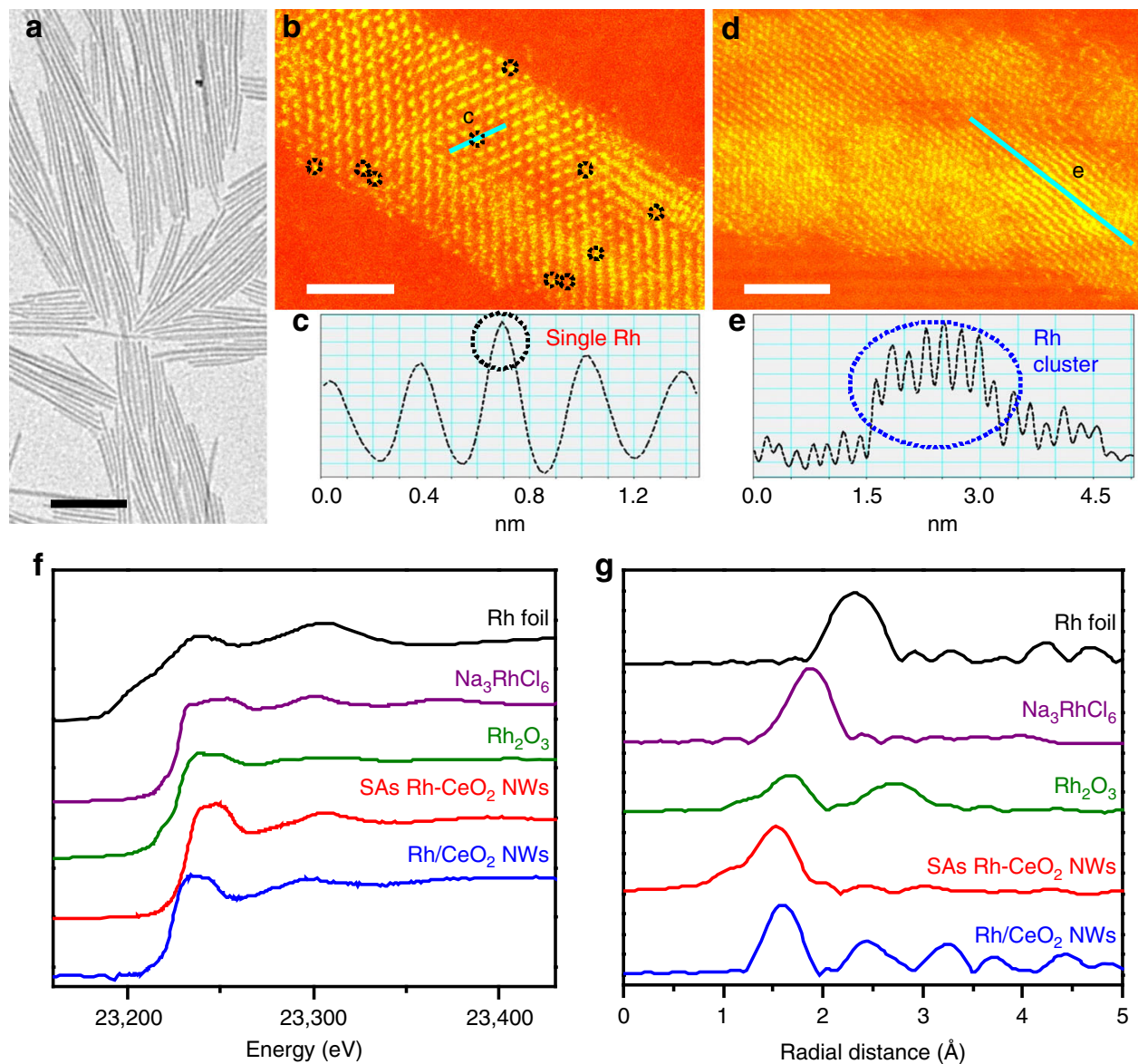

Fig. 1 Structural analyses of $\mathbf{S A s} \mathbf{R h}-\mathbf{C e O}_{\mathbf{2}} \mathbf{N W s}$ and $\mathbf{R h} / \mathbf{C e O}_{\mathbf{2}} \mathbf{~ N W s . ~ a ~ T E M ~ i m a g e ~ o f ~ t h e ~} \mathrm{SAs} \mathrm{Rh}-\mathrm{CeO}_{2} \mathrm{NWs}$. $\mathbf{b}$ AC-HAADF/STEM image in temperature color of the $\mathrm{SAs} \mathrm{Rh}-\mathrm{CeO}_{2} \mathrm{NWs}$. The isolated Rh atoms are marked with black circles. $\mathbf{c}$ The intensity profile recorded from the line in panel (b). $\mathbf{d}$ AC$\mathrm{HAADF} / \mathrm{STEM}$ image in temperature color of the $\mathrm{Rh} / \mathrm{CeO}_{2} \mathrm{NWs}$. The Rh cluster is marked with blue line. e The intensity profile recorded from the line in panel (d). f, $\mathbf{g}$ Rh K-edge XANES spectra (f) and Rh K-edge EXAFS spectra in $R$ space (g) of the Rh foil, $\mathrm{Na}_{3} \mathrm{RhCl}_{6}, \mathrm{Rh}_{2} \mathrm{O}_{3}, \mathrm{SAs}_{\mathrm{Rh}}-\mathrm{CeO}_{2} \mathrm{NWs}_{1}$ and Rh/CeO NWs. The scale bars in (a), (b), and (d) are 100, 2, and $2 \mathrm{~nm}$, respectively.

comparison with $\mathrm{Rh} / \mathrm{CeO}_{2}$ NWs and $\mathrm{Rh} / \mathrm{CeO}_{2}$-com. No obvious peaks in $\mathrm{Na} 1 \mathrm{~s}$ and $\mathrm{Cl} 2 \mathrm{p}$ XPS spectra suggest that neglect amount of $\mathrm{Na}$ and $\mathrm{Cl}$ remain on catalysts (Supplementary Fig. $5 \mathrm{c}, \mathrm{d}$ ).

To study the electronic structures and coordination states of $\mathrm{Rh}$ in the SAs $\mathrm{Rh}-\mathrm{CeO}_{2} \mathrm{NWs}$ and the $\mathrm{Rh} / \mathrm{CeO}_{2} \mathrm{NWs}$, X-ray absorption near-edge spectroscopy (XANES) and extended Xray fine structure (EXAFS) were measured at $\mathrm{Rh} \mathrm{K}$-edge. Rh foil, $\mathrm{Rh}_{2} \mathrm{O}_{3}$, and $\mathrm{Na}_{3} \mathrm{RhCl}_{6}$ were used as references. Comparing with the edge position in the XANES spectra of references, $\mathrm{Rh}$ in SAs $\mathrm{Rh}-\mathrm{CeO}_{2} \mathrm{NWs}$ and $\mathrm{Rh} / \mathrm{CeO}_{2} \mathrm{NWs}$ are presented as their oxidation states (Fig. 1f). As shown in Fig. 1g, the $\mathrm{Rh}-\mathrm{Rh}$ coordination, $\mathrm{Rh}-\mathrm{Cl}$ coordination, $\mathrm{Rh}-\mathrm{O}$, and the second shell of $\mathrm{Rh}-\mathrm{O}$ coordination are observed at $\sim 2.3 \AA, \sim 1.9 \AA, \sim 1.7 \AA$, and $\sim 2.7 \AA$, respectively ${ }^{15}$. For $\mathrm{Rh} / \mathrm{CeO}_{2} \mathrm{NWs}, \mathrm{Rh}-\mathrm{O}$, and $\mathrm{Rh}-\mathrm{Rh}$ coordination appear at $\sim 1.6 \AA$ and $\sim 2.4 \AA$ in the $R$-space EXAFS spectrum, indicating the presence of Rh clusters in $\mathrm{Rh} / \mathrm{CeO}_{2} \mathrm{NWs}$. By contrast, only the feature of $\mathrm{Rh}-\mathrm{O}$ coordination at $\sim 1.6 \AA$ is observed in the R-space spectrum of $\mathrm{SAs} \mathrm{Rh}-\mathrm{CeO}_{2} \mathrm{NWs}$ (Fig. 1g). The disappearance of $\mathrm{Rh}-\mathrm{Rh}$ coordination implies that $\mathrm{Rh}$ atoms in SAs Rh- $-\mathrm{CeO}_{2} \mathrm{NWs}$ are presented as isolated atoms, which is in good agreement with the observations in AC-HAADF/STEM image ${ }^{16,23}$. It is noted that no obvious $\mathrm{Rh}-\mathrm{Cl}$ coordination is observed in the EXAFS spectrum of $\mathrm{SAs} \mathrm{Rh}-\mathrm{CeO}_{2} \mathrm{NWs}$, indicating that the $\mathrm{Rh}$ atoms are anchored by $\mathrm{O}$ atoms in $\mathrm{CeO}_{2}$ $\mathrm{NWs}$ via $\mathrm{Rh}-\mathrm{O}$ coordination. In addition, the structures of SAs $\mathrm{Rh}-\mathrm{CeO}_{2} \mathrm{NWs}$ and $\mathrm{Rh} / \mathrm{CeO}_{2}$ NWs were verified by the diffuse reflectance-infrared Fourier transform spectroscopy (DRIFTS) measurement using $\mathrm{CO}$ as a probe. As shown in Supplementary Fig. 6a, different from the previous reports that Rh SA gives geminal peaks in $2000-2100 \mathrm{~cm}^{-1}$, only one broad and weak peak is observed at $2000-2150 \mathrm{~cm}^{-1}$ in the CO-DRIFTS spectrum of SAs Rh- $\mathrm{CeO}_{2} \mathrm{NWs}$, which may be attributed to the low $\mathrm{CO}$ coverage on $\mathrm{SAs} \mathrm{Rh}-\mathrm{CeO}_{2} \mathrm{NWs}^{24}$. The presence of oxidation species at $1250-1700 \mathrm{~cm}^{-1}$ indicates that the adsorbed $\mathrm{CO}$ molecules are oxidized, further confirming the low $\mathrm{CO}$ coverage on the surface of SAs Rh- $\mathrm{CeO}_{2} \mathrm{NWs}$. When SAs Rh$\mathrm{CeO}_{2} \mathrm{NWs}$ was pretreated in $\mathrm{CO}$ at $50^{\circ} \mathrm{C}$ for $0.5 \mathrm{~h}$, the intensity of peak at $2000-2150 \mathrm{~cm}^{-1}$ obviously increases, despite the appearance of oxidation species. Further increasing the pretreatment temperature to $150^{\circ} \mathrm{C}$, two intense peaks appear at 2101 and $2030 \mathrm{~cm}^{-1}$ in CO-DRIFTS spectrum of SAs Rh-CeO ${ }_{2} \mathrm{NWs}$, which correspond to the symmetric and asymmetric vibration of gem-dicarbonyl doublet $\mathrm{CO}$ (i.e., $\mathrm{Rh}(\mathrm{CO})_{2}$ ) (Supplementary Fig. 6a, red curve $)^{25}$. For $\mathrm{Rh} / \mathrm{CeO}_{2} \mathrm{NWs}$, in addition to the peaks of oxidation species, multiple peaks corresponding to the symmetric $\left(2101 \mathrm{~cm}^{-1}\right)$ and asymmetric vibration $\left(2030 \mathrm{~cm}^{-1}\right)$ of $\mathrm{Rh}(\mathrm{CO})_{2}$ and $\mathrm{CO}$ linear adsorption on $\mathrm{Rh}^{\delta+}\left(2133 \mathrm{~cm}^{-1}\right)$ are observed in CO-DRIFTS spectrum (Supplementary Fig. 6b). When $\mathrm{Rh} / \mathrm{CeO}_{2} \mathrm{NWs}$ was pretreated at $50^{\circ} \mathrm{C}$ and then $150^{\circ} \mathrm{C}$ for $0.5 \mathrm{~h}$, two peaks appear at 1860 and $2060 \mathrm{~cm}^{-1}$ in CO-DRIFTS spectrum, which correspond to the $\mathrm{CO}$ bridge adsorption and linear adsorption on Rh, respectively (Supplementary Fig. 6b, red curve $)^{24,25}$. The absence of $\mathrm{CO}$ bridge adsorption in the CODRIFTS spectrum further confirms the structures of Rh SA in SAs 
a

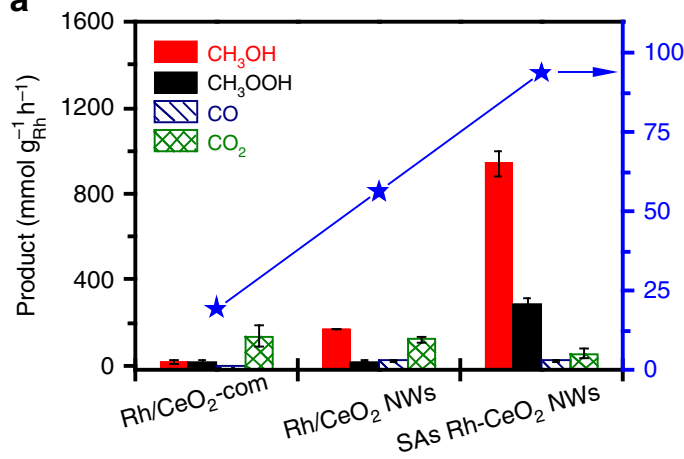

C

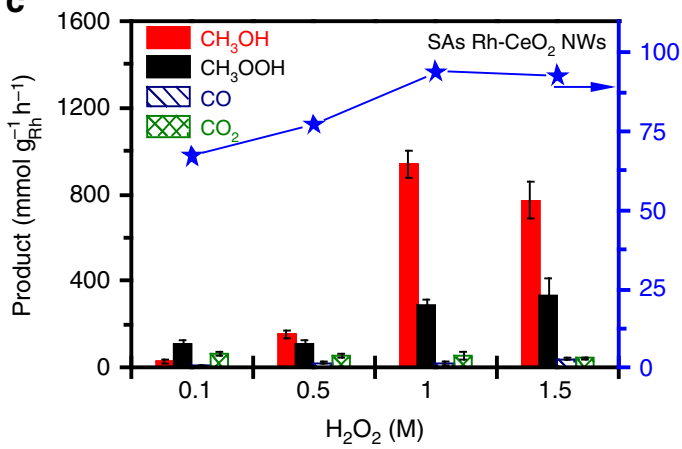

b

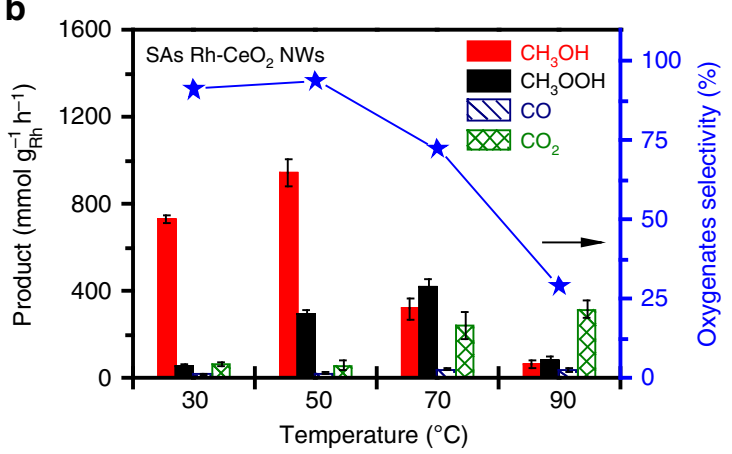

d

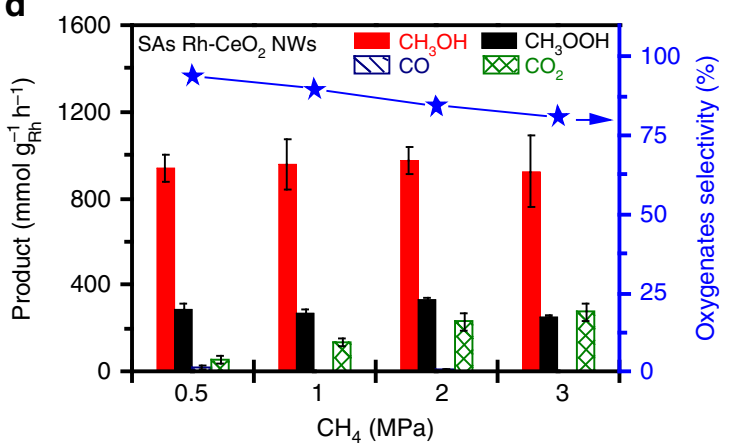

Fig. 2 DMC performance on different catalysts. a The yield and selectivity of oxygenates from $\mathrm{Rh} / \mathrm{CeO}_{2}-\mathrm{com} \mathrm{Rh} / \mathrm{CeO} 2 \mathrm{NWs}$, and $\mathrm{SAs} \mathrm{Rh}-\mathrm{CeO} 2 \mathrm{NWs}$. Reaction conditions: $P_{\mathrm{CH} 4}: 0.5 \mathrm{MPa}, \mathrm{H}_{2} \mathrm{O}_{2}: 20 \mathrm{~mL}(1 \mathrm{M}), \mathrm{T}: 50^{\circ} \mathrm{C}$, reaction time: $1 \mathrm{~h}$, and catalyst weight: $10 \mathrm{mg}$. $\mathbf{b}$ DMC performance at different temperatures over $\mathrm{SAs} \mathrm{Rh}-\mathrm{CeO}_{2} \mathrm{NWs}$. Reaction conditions: $\mathrm{P}_{\mathrm{CH} 4}: 0.5 \mathrm{MPa}, \mathrm{H}_{2} \mathrm{O}_{2}: 20 \mathrm{~mL}(1 \mathrm{M}), \mathrm{T}: 30-90^{\circ} \mathrm{C}$, reaction time: $1 \mathrm{~h}$, and catalyst weight: $10 \mathrm{mg}$. c DMC performance at different $\mathrm{H}_{2} \mathrm{O}_{2}$ concentrations over $\mathrm{SAs}$ Rh- $\mathrm{CeO}_{2} \mathrm{NWs}$. Reaction conditions: $P_{\mathrm{CH} 4}: 0.5 \mathrm{MPa}, \mathrm{H}_{2} \mathrm{O}_{2}: 20 \mathrm{~mL}(0.1-1.5 \mathrm{M}), \mathrm{T}: 50{ }^{\circ} \mathrm{C}$, reaction time: $1 \mathrm{~h}$, and catalyst weight: $10 \mathrm{mg}$. d DMC performance at different $\mathrm{CH}_{4}$ partial pressure over $\mathrm{SAs}$ Rh- $\mathrm{CeO}_{2} \mathrm{NWs}$. Reaction conditions: $P_{\mathrm{CH}}$ : 0.5-3 MPa, $\mathrm{H}_{2} \mathrm{O}_{2}: 20 \mathrm{~mL}(1 \mathrm{M}), \mathrm{T}: 50^{\circ} \mathrm{C}$, reaction time: $1 \mathrm{~h}$, and catalyst weight: $10 \mathrm{mg}$. The error bars are defined as standard deviation of three experiments.

Rh- $\mathrm{CeO}_{2}$ NWs, which is in good agreement with the result of ACHAADF/STEM and X-ray absorption spectroscopy ${ }^{25}$.

DMC performance of SAs Rh- $\mathrm{CeO}_{2} \mathrm{NWs}$ and $\mathrm{Rh} / \mathrm{CeO}_{2} \mathrm{NWs}$. All the catalysts of $\mathrm{Rh} / \mathrm{CeO}_{2}-\mathrm{com}, \mathrm{Rh} / \mathrm{CeO}_{2} \mathrm{NWs}$, and SAs Rh$\mathrm{CeO}_{2}$ NWs were used for DMC in a pressurized reactor. Products were analyzed by gas chromatography and ${ }^{1} \mathrm{H}$ nuclear magnetic resonance spectroscopy $\left({ }^{1} \mathrm{H}-\mathrm{NMR}\right)$. As shown in Fig. 2a, Rh/ $\mathrm{CeO}_{2}$-com gives the $\mathrm{CH}_{3} \mathrm{OH}, \mathrm{CH}_{3} \mathrm{OOH}$, and $\mathrm{CO}_{\mathrm{x}}$ yield of 17.6, 15.6, and $137.4 \mathrm{mmol} \mathrm{g}_{\mathrm{Rh}}{ }^{-1} \mathrm{~h}^{-1}$, respectively. When $\mathrm{Rh} / \mathrm{CeO}_{2}$ NWs are used as a catalyst, the yield of $\mathrm{CH}_{3} \mathrm{OH}$ and $\mathrm{CH}_{3} \mathrm{OOH}$ increase to $170.4 \mathrm{mmol} \mathrm{g}_{\mathrm{Rh}}{ }^{-1} \mathrm{~h}^{-1}$ and $19.0 \mathrm{mmol} \mathrm{g}_{\mathrm{Rh}}{ }^{-1} \mathrm{~h}^{-1}$, respectively, while the total yield of $\mathrm{CO}_{\mathrm{x}}$ is $146.3 \mathrm{mmol} \mathrm{g}_{\mathrm{Rh}}{ }^{-1} \mathrm{~h}^{-1}$. The low selectivities of oxygenate on $\mathrm{Rh} / \mathrm{CeO}_{2}-\mathrm{com}(19.5 \%)$ and $\mathrm{Rh} / \mathrm{CeO}_{2} \mathrm{NWs}$ (56.4\%) indicate that $\mathrm{CH}_{4}$ tends to be overoxidized into $\mathrm{CO}_{\mathrm{x}}$ on $\mathrm{Rh} / \mathrm{CeO}_{2}$-com and $\mathrm{Rh} / \mathrm{CeO}_{2} \mathrm{NWs}$. By contrast, when SAs Rh- $\mathrm{CeO}_{2} \mathrm{NWs}$ are used as a catalyst, the selectivity of $\mathrm{CO}_{\mathrm{x}}$ significantly decreases to $6.1 \%$, indicating that the overoxidation of $\mathrm{CH}_{4}$ is strongly suppressed on $\mathrm{SAs} \mathrm{Rh}-\mathrm{CeO}_{2}$ NWs. Correspondingly, the yield of $\mathrm{CH}_{3} \mathrm{OH}$ and $\mathrm{CH}_{3} \mathrm{OOH}$ significantly increase to 940.3 and $291.4 \mathrm{mmol} \mathrm{g}_{\mathrm{Rh}}{ }^{-1} \mathrm{~h}^{-1}$, respectively. Moreover, SAs Rh- $\mathrm{CeO}_{2} \mathrm{NWs}$ were tested for DMC under different conditions (i.e., temperature, $\mathrm{H}_{2} \mathrm{O}_{2}$ concentration, $\mathrm{CH}_{4}$ pressure, and catalysts amount). As depicted in Fig. 2b, it is found that the increase of temperature leads to a volcano-shape selectivity and yield of oxygenates. Typically, the selectivity and yield of oxygenates are $91.4 \%$ and $786.3 \mathrm{mmol} \mathrm{g}_{\mathrm{Rh}}{ }^{-1} \mathrm{~h}^{-1}$ at $30^{\circ} \mathrm{C}$, which further increases to $93.9 \%$ and $1231.7 \mathrm{mmol} \mathrm{g}_{\mathrm{Rh}}{ }^{-1} \mathrm{~h}^{-1}$ at $50{ }^{\circ} \mathrm{C}$. Further increase in temperature will lead to a decrease in both the selectivity and yield of oxygenates. A similar tendency is observed when the concentration of $\mathrm{H}_{2} \mathrm{O}_{2}$ is increased from 0.1 to $1.5 \mathrm{M}$ (Fig. 2c). For instance, the selectivity and yield of oxygenates are $67.1 \%$ and $145.0 \mathrm{mmol} \mathrm{gRh}^{-1} \mathrm{~h}^{-1}$ at the $\mathrm{H}_{2} \mathrm{O}_{2}$ concentration of $0.1 \mathrm{M}$, which significantly increase to $93.9 \%$ and $1231.7 \mathrm{mmol} \mathrm{g}_{\mathrm{Rh}}{ }^{-1} \mathrm{~h}^{-1}$ at the $\mathrm{H}_{2} \mathrm{O}_{2}$ concentration of $1.0 \mathrm{M}$, indicating $\mathrm{H}_{2} \mathrm{O}_{2}$ can significantly promote the DMC activity. It is noted that a further increase of $\mathrm{H}_{2} \mathrm{O}_{2}$ concentration to $1.5 \mathrm{M}$ will result in a slight decay in oxygenates selectivity and yield. Furthermore, the effects of $\mathrm{CH}_{4}$ partial pressure on DMC performance were studied. As shown in Fig. 2d, the selectivity of $\mathrm{CO}_{x}$ strongly increases from $6.1 \%$ to $21.1 \%$ when the $\mathrm{CH}_{4}$ partial pressure is increased from $0.5 \mathrm{MPa}$ to $3 \mathrm{MPa}$, despite the similar yield of oxygenates. We thus further tested the DMC performance by altering the weight of the catalyst, as shown in Supplementary Fig. 7. It is found that the yield of $\mathrm{CH}_{3} \mathrm{OH}$ and $\mathrm{CH}_{3} \mathrm{OOH}$ steadily increase as the increasing weight of catalyst, while the selectivity of $\mathrm{CH}_{3} \mathrm{OH}$ and $\mathrm{CH}_{3} \mathrm{OOH}$ are kept at $\sim 94 \%$. The positive effects of $\mathrm{H}_{2} \mathrm{O}_{2}$ concentration and catalyst weight but negligible effects of $\mathrm{CH}_{4}$ partial pressure on the oxygenates selectivity imply that $\mathrm{Rh}$ SA can efficiently activate $\mathrm{C}-\mathrm{H}$ bonds in $\mathrm{CH}_{4}$ under the optimized conditions, and the rate-determining steps solely involve the reaction of $\mathrm{CH}_{4}$ activation intermediates with $\mathrm{H}_{2} \mathrm{O}_{2}$ (Fig. 2; Supplementary Fig. 7) ${ }^{10}$. In addition, SAs Rh- $\mathrm{CeO}_{2} \mathrm{NWs}$ were used in ten consecutive DMC cycles to test the stability. As shown in Supplementary Fig. 8, no obvious decays in oxygenates selectivity and yield are observed after ten consecutive DMC cycles. The structures of Rh SA are reserved in the spent SAs $\mathrm{Rh}-\mathrm{CeO}_{2}$ NWs, indicating that SAs Rh- $\mathrm{CeO}_{2} \mathrm{NWs}$ can be used as a stable catalyst for DMC (Supplementary Fig. 9). Moreover, to the best of 
our knowledge, the current DMC performance has outperformed the reported catalysts (Supplementary Table 2), suggesting that SAs Rh- $-\mathrm{CeO}_{2}$ NWs can be used as a highly efficient catalyst for DMC to oxygenates under mild conditions.

Mechanistic studies on DMC. In order to study the mechanism of $\mathrm{CH}_{4}$ selective oxidation on SAs $\mathrm{Rh}-\mathrm{CeO}_{2} \mathrm{NWs}$, DMC was performed using $\mathrm{O}_{2}$ as the oxidant to replace $\mathrm{H}_{2} \mathrm{O}_{2}$. As depicted in Supplementary Table 3, the selectivity of oxygenates is $5.9 \%$ when $\mathrm{O}_{2}$ is solely used as the oxidant, which significantly increases to $92.8 \%$ after the addition of $10 \mu \mathrm{mol} \mathrm{H}_{2} \mathrm{O}_{2}$. Correspondingly, the yield of oxygenates increases from 17.6 to 1159.4 mmol ghh ${ }^{-1} \mathrm{~h}^{-1}$, indicating that $\mathrm{H}_{2} \mathrm{O}_{2}$ can significantly promote DMC to oxygenates. Based on the previous reports ${ }^{10}$, we speculated that the DMC in the presence of $\mathrm{H}_{2} \mathrm{O}_{2}$ might follow radicaltriggered reaction paths. Therefore, electron paramagnetic resonance (EPR) was performed to detect the radicals in the present reaction system by using 5,5'-dimethyl-1-pyrroline-N-oxide (DMPO) as the radical scavenger. In order to label the radicals, two contrast experiments were performed in the systems of $\mathrm{DMPO}+\mathrm{H}_{2} \mathrm{O}_{2}+\mathrm{Fe}^{2+}$ and $\mathrm{DMPO}+\mathrm{H}_{2} \mathrm{O}_{2}+\mathrm{Fe}^{2+}+\mathrm{CH}_{3} \mathrm{OH}$ (detailed information has been given in the experimental section). As shown in Supplementary Fig. 10, a four-line EPR spectrum with a relative peak ratio of 1:2:2:1 is obtained from the DMPO + $\mathrm{H}_{2} \mathrm{O}_{2}+\mathrm{Fe}^{2+}$ system (Supplementary Fig. 10, green curve), which can be assigned to $\cdot \mathrm{OH}$ radical $^{26}$. For the system of DMPO + $\mathrm{H}_{2} \mathrm{O}_{2}+\mathrm{Fe}^{2+}+\mathrm{CH}_{3} \mathrm{OH}$, a six-line EPR spectrum is recorded, which can be indexed as the characteristic peaks of $\cdot \mathrm{CH}_{3}$ radical (Supplementary Fig. 10, blue curve) ${ }^{26}$. When DMPO is added into the reaction system, some new peaks of $\cdot \mathrm{OOH}$ appear in the EPR spectrum in addition to those peaks of $\mathrm{CH}_{3}$ and $\mathrm{OH}$ radicals (Supplementary Fig. 10, red curve) ${ }^{27}$. The presence of $\cdot \mathrm{CH}_{3}, \mathrm{OOH}$, and $\cdot \mathrm{OH}$ radicals in the reaction system further confirms that the DMC on the SAs Rh- $\mathrm{CeO}_{2}$ NWs in $\mathrm{H}_{2} \mathrm{O}_{2}$ solution is triggered by radicals.

To further study the working mechanism of the radicaltriggered DMC on SAs $\mathrm{Rh}-\mathrm{CeO}_{2} \mathrm{NWs}$, in situ DRIFTS measurements were performed to analyze the surface species on SAs $\mathrm{Rh}-\mathrm{CeO}_{2} \mathrm{NWs}$ and $\mathrm{Rh} / \mathrm{CeO}_{2} \mathrm{NWs}$ when they were exposed to $\mathrm{H}_{2} \mathrm{O}_{2}$ and $\mathrm{CH}_{4}$. First, we exposed SAs Rh- $\mathrm{CeO}_{2} \mathrm{NWs}$ and $\mathrm{Rh} /$ $\mathrm{CeO}_{2}$ NWs into $\mathrm{H}_{2} \mathrm{O}_{2}$. As shown in Supplementary Fig. 11, three intense peaks are observed at 3401,3214 , and $1654 \mathrm{~cm}^{-1}$ in the spectra of SAs Rh- $-\mathrm{CeO}_{2} \mathrm{NWs}$ and $\mathrm{Rh} / \mathrm{CeO}_{2} \mathrm{NWs}$, which can be assigned to ${ }^{*} \mathrm{OH},{ }^{*} \mathrm{OOH}$, and ${ }^{*} \mathrm{OH}_{2}$, respectively ${ }^{28}$. Based on the observations in EPR spectra (Supplementary Fig. 10) and previous reports, we conclude that $\mathrm{H}_{2} \mathrm{O}_{2}$ can decompose into active radicals on $\mathrm{CeO}_{2} \mathrm{NWs}^{29,30}$. When the $\mathrm{SAs} \mathrm{Rh}-\mathrm{CeO}_{2} \mathrm{NWs}$ are exposed to $\mathrm{CH}_{4}$, the characteristic bands of ${ }^{*} \mathrm{CH}_{3}$ appear at 1412 and $1304 \mathrm{~cm}^{-1}$ (see ref. ${ }^{31}$ ), indicating that $\mathrm{SAs} \mathrm{Rh}-\mathrm{CeO}_{2}$ NWs can selectively activate $\mathrm{CH}_{4}$ into ${ }^{*} \mathrm{CH}_{3}$ (Fig. 3a, black curve). Moreover, two additional bands are observed at 1635 and 3401 $\mathrm{cm}^{-1}$, which can be ascribed as ${ }^{*} \mathrm{OH}_{2}$ and ${ }^{*} \mathrm{OH}$, respectively, suggesting that ${ }^{*} \mathrm{OH}$ may combine with $\mathrm{H}$ from $\mathrm{CH}_{4}$ decomposition to form ${ }^{*} \mathrm{OH}_{2}$. When $\mathrm{SAs} \mathrm{Rh}-\mathrm{CeO}_{2} \mathrm{NWs}$ are exposed to the mixture of $\mathrm{CH}_{4}$ and $\mathrm{H}_{2} \mathrm{O}_{2}$ (Fig. $3 \mathrm{a}$, red curve), new peaks appear at $2935,2837,1438,1353,1220$, and $1148 \mathrm{~cm}^{-1}$ in the spectrum, which can be assign to the $\mathrm{C}-\mathrm{H}$ asymmetric stretching vibration, $\mathrm{C}-\mathrm{H}$ symmetric stretching vibration, $\mathrm{CH}_{3}$ scissoring vibration, $\mathrm{CH}_{3}$ asymmetric rocking vibration, $\mathrm{C}-\mathrm{O}$ stretching vibration and $\mathrm{CH}_{3}$ symmetric rocking vibration of ${ }^{*} \mathrm{OCH}_{3}$, respectively ${ }^{32,33}$. The appearance of ${ }^{*} \mathrm{OCH}_{3},{ }^{*} \mathrm{OH}$, and ${ }^{*} \mathrm{OOH}$ demonstrates the formation of $\mathrm{CH}_{3} \mathrm{OH}$ and $\mathrm{CH}_{3} \mathrm{OOH}$. By contrast, when $\mathrm{Rh} / \mathrm{CeO}_{2}$ NWs are exposed to $\mathrm{CH}_{4}$, only two strong bands of $\mathrm{CO}_{3}{ }^{2-}$ and ${ }^{*} \mathrm{CO}_{2}{ }^{\delta-}$ are observed at 1589 and $1293 \mathrm{~cm}^{-1}$ (Fig. 3b, black spectrum) ${ }^{34}$. The absence of ${ }^{*} \mathrm{CH}_{3}$,
${ }^{*} \mathrm{OH}$, and ${ }^{*} \mathrm{OH}_{2}$ suggests that $\mathrm{CH}_{4}$ is overoxidized into $\mathrm{CO}_{\mathrm{x}}$ species. When $\mathrm{Rh} / \mathrm{CeO}_{2} \mathrm{NWs}$ are exposed to the mixture of $\mathrm{CH}_{4}$ and $\mathrm{H}_{2} \mathrm{O}_{2}$, the intense band of $\mathrm{CO}_{3}{ }^{2-}$ in the spectrum implies that $\mathrm{CO}_{\mathrm{x}}$ are the dominate products despite the appearance of ${ }^{*} \mathrm{OCH}_{3}$ and ${ }^{*} \mathrm{OH}$ bands (Fig. 3b, blue curve) ${ }^{35}$, which is consistent with our experimental results (Fig. 2a).

To further confirm the activation of $\mathrm{CH}_{4}$ on $\mathrm{Rh}, \mathrm{CH}_{4}$ temperature programmed surface reaction (TPSR) was performed to investigate the $\mathrm{CH}_{4}$ conversion on $\mathrm{CeO}_{2} \mathrm{NWs}$, SAs Rh- $\mathrm{CeO}_{2}$ NWs, and $\mathrm{Rh} / \mathrm{CeO}_{2} \mathrm{NWs}$. No obvious peaks are observed in the TPSR pattern of $\mathrm{CeO}_{2} \mathrm{NWs}$, suggesting that $\mathrm{CeO}_{2}$ NWs are inactive for $\mathrm{CH}_{4}$ activation under the indicated conditions (Supplementary Fig. 12). When $\mathrm{CH}_{4}$-TPSR measurements were performed on SAs Rh- $-\mathrm{CeO}_{2} \mathrm{NWs}$ and $\mathrm{Rh} / \mathrm{CeO}_{2} \mathrm{NWs}$, the peaks of $\mathrm{CH}_{4}, \mathrm{CO}, \mathrm{CO}_{2}$, and $\mathrm{H}_{2} \mathrm{O}$ appear in TPSR patterns, suggesting that $\mathrm{Rh}$ atoms play as the active sites for $\mathrm{CH}_{4}$ activation (Fig. 3c, d), which is in good agreement with results from the in situ DRIFTS measurement (Fig. 3a, b). Despite the appearance of peaks in TPSR patterns, the different onset temperatures $\left(T_{\text {onset }}\right)$ suggest that the reaction paths are different on $\mathrm{SAs} \mathrm{Rh}-\mathrm{CeO}_{2}$ NWs and $\mathrm{Rh} / \mathrm{CeO}_{2} \mathrm{NWs}$ (Fig. 3c, d). For SAs Rh- $\mathrm{CeO}_{2} \mathrm{NWs}$, the $T_{\text {onset }}$ of $\mathrm{CH}_{4}\left(\sim 82^{\circ} \mathrm{C}\right.$, formed via ${ }^{*} \mathrm{CH}_{3}$ hydrogenation $)$ is closed to that of $\mathrm{CO}\left(\sim 82^{\circ} \mathrm{C}\right)$ and $\mathrm{CO}_{2}\left(\sim 82^{\circ} \mathrm{C}\right)$, indicating that ${ }^{*} \mathrm{CH}_{3}$ hydrogenation (to form $\mathrm{CH}_{4}$ ) and overdehydrogenation (to form $\mathrm{CO}_{\mathrm{x}}$ ) competitively occur on the SAs Rh- $\mathrm{CeO}_{2} \mathrm{NWs}$. By contrast, the $T_{\text {onset }}$ of $\mathrm{CO}_{2}\left(\sim 67^{\circ} \mathrm{C}\right)$ and $\mathrm{CO}\left(\sim 61^{\circ} \mathrm{C}\right)$ is significantly lower than that of $\mathrm{CH}_{4}\left(\sim 74^{\circ} \mathrm{C}\right)$ in TPSR patterns of $\mathrm{Rh} / \mathrm{CeO}_{2} \mathrm{NWs}$, indicating that overoxidation for the formation of $\mathrm{CO}$ and $\mathrm{CO}_{2}$ is preferential ${ }^{5}$.

DFT calculations. Finally, DFT calculations were performed to reveal the reaction paths of $\mathrm{CH}_{4}$ oxidation on $\mathrm{SAs} \mathrm{Rh}-\mathrm{CeO}_{2} \mathrm{NWs}$ and $\mathrm{Rh} / \mathrm{CeO}_{2}$ NWs. The real spatial orbital distribution apparently shows the concentrated electron-rich feature on $\mathrm{SAs} R \mathrm{Rh}$, which indicates the $\mathrm{Rh}$ site possesses a superior reaction priority among the available sites on the surface. Meanwhile, Rh cluster on $\mathrm{CeO}_{2}$ shows widely separated electronic distribution over the surface, which shows the disperse electroactive region (Fig. 4a). The projected density of states (PDOS) support that the highly concentrated electronic activity of SAs Rh on the surfaces is attributed to the sharp Rh-4d occupation near the Fermi level $\left(\mathrm{E}_{\mathrm{F}}\right)$. The Ce-4f bands mainly locate above $\mathrm{E}_{\mathrm{F}}$, while $\mathrm{O}-2 \mathrm{p}$ bands concentrate on $\mathrm{E}_{\mathrm{v}}-4.5 \mathrm{eV}$. The evident coupling between Rh- $4 \mathrm{~d}$ and Ce- $4 \mathrm{~d}$ confirms the stabilization of SAs Rh by the protection of bottom Ce (Fig. 4b). In comparison, the Rh-4d bands become much broad in $\mathrm{Rh} / \mathrm{CeO}_{2}$, covering from $\mathrm{E}_{\mathrm{v}}-5.0 \mathrm{eV} \mathrm{E} \mathrm{v}+2.0 \mathrm{eV}$. The evident match among Rh- $4 \mathrm{~d}$ bands and $\mathrm{O}-2 \mathrm{p}$ bands and $\mathrm{Ce}-$ 4f bands indicates a strong coupling between the surface $\mathrm{Rh}$ cluster and bottom $\mathrm{CeO}_{2}$ (Fig. 4c). The electronic structures of $\mathrm{CH}_{4}$ adsorption are further presented to illustrate the different activity toward the DMC process. It is noted the dominant peak of Rh-4d in SAs Rh- $\mathrm{CeO}_{2}$ upshifts from $\mathrm{E}_{\mathrm{v}}-2.0 \mathrm{eV}$ toward $\mathrm{E}_{\mathrm{v}}-1.0 \mathrm{eV}$ due to the electron transfer with $\mathrm{CH}_{4}$ (Fig. $4 \mathrm{~d}$ ). Meanwhile, the close distance between $\mathrm{Rh}-4 \mathrm{~d}$ bands and $\mathrm{O}-2 \mathrm{p}$ bands on $\mathrm{Rh} / \mathrm{CeO}_{2}$ NWs demonstrates the strong couplings between $\mathrm{CH}_{4}$ and local $\mathrm{O}$ atoms, which lead to the over-binding effect with increased energy barriers for the consecutive dehydrogenation of $\mathrm{CH}_{4}$ (Fig. 4e).

Since EPR and in situ DRIFTS results show that lattice $\mathrm{O}$ atoms of $\mathrm{CeO}_{2}$ are feasibly bonded with $\mathrm{H}$ in $\mathrm{H}_{2} \mathrm{O}_{2}$. From the energetic view, DFT also proves the superior flexibility of $\mathrm{O}$ in SAs Rh$\mathrm{CeO}_{2} \mathrm{NWs}$ with only $0.16 \mathrm{eV}$ energy barrier. Due to the steric hindrance from the surface coverage of $\mathrm{Rh}$ cluster, the energy barrier of the detachment of $\mathrm{O}$ in $\mathrm{Rh} / \mathrm{CeO}_{2}$ NWs increases to $4.06 \mathrm{eV}$, demonstrating a slow efficiency of generating $\cdot \mathrm{OOH}$ 

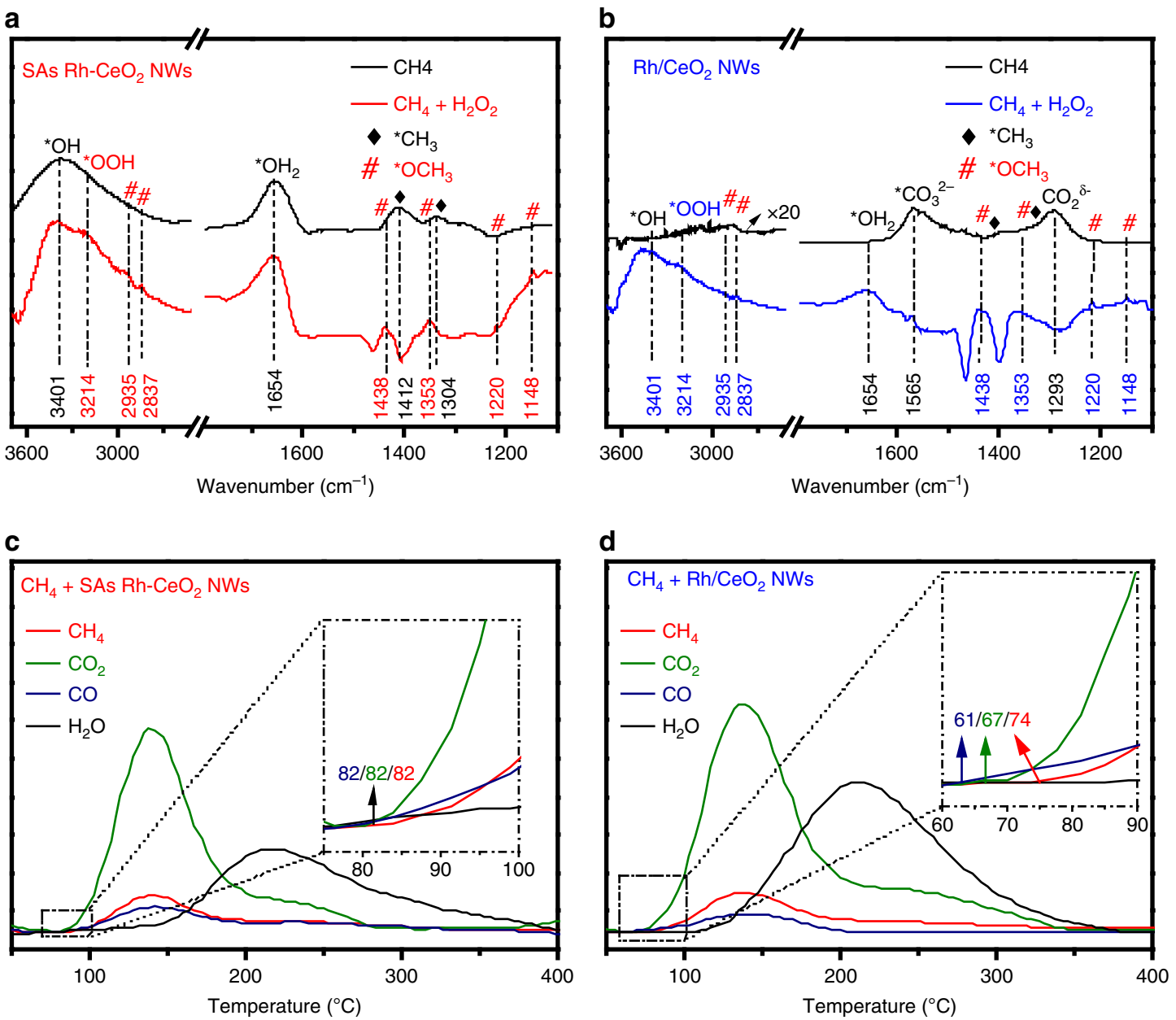

Fig. 3 In situ $\mathbf{C H}_{\mathbf{4}}$-DRIFTS and $\mathbf{C H}_{\mathbf{4}}$-TPSR measurement. a, b In situ $\mathrm{CH}_{4}$-DRIFTS measurements on $\mathrm{SAs}$ Rh- $\mathrm{CeO}_{2} \mathrm{NWs}(\mathbf{a})$ and Rh/CeO 2 NWs (b). c, d $\mathrm{CH}_{4}$-TPSR measurements on $\mathrm{SAs} \mathrm{Rh}-\mathrm{CeO}_{2} \mathrm{NWs}$ (c) and $\mathrm{Rh} / \mathrm{CeO}_{2} \mathrm{NWs}(\mathbf{d})$.

radicals (Fig. 4f). The further reaction energies also support that the generations of both $\cdot \mathrm{OH}$ and $\cdot \mathrm{OOH}$ radicals are much more preferred in $\mathrm{SAs} \mathrm{Rh}-\mathrm{CeO}_{2} \mathrm{NWs}$, satisfying the prerequisite of radical-mediated DMC process (Fig. $4 \mathrm{~g}$ ). The $\mathrm{SAs} \mathrm{Rh}-\mathrm{CeO}_{2} \mathrm{NWs}$ deliver an overall downhill trend to the formation final product $\mathrm{CH}_{3} \mathrm{OH}$ and $\mathrm{CH}_{3} \mathrm{OOH}$, representing a high electronic activity. The spontaneous adsorption of $\mathrm{CH}_{4}$ and facile $\mathrm{C}-\mathrm{H}$ bond cleavage indicates the fast activation of $\mathrm{C}-\mathrm{H}$ bond, which leads to the efficient DMC process. Particularly, the further reaction of $\mathrm{CH}_{3} \mathrm{OOH}$ toward $\mathrm{HCOOH}$ has been suppressed by the high energetic barrier of $1 \mathrm{eV}$, guaranteeing the reaction locking for desired products. The formation of $\mathrm{CH}_{3} \mathrm{OH}$ releases $2.87 \mathrm{eV}$, which is slightly larger energy than that of $\mathrm{CH}_{3} \mathrm{OOH}(2.53 \mathrm{eV})$, explaining the higher yield of oxygenates in our experiments. Meanwhile, the high energy cost $(2.01 \mathrm{eV})$ to achieve further $\mathrm{C}$ $-\mathrm{H}$ bond cleavage of $\mathrm{CH}_{3}$ facilitates the high selectivity of DMC on the SAs Rh- $\mathrm{CeO}_{2}$ NWs (Fig. 4h). In contrast, the activation of $\mathrm{C}-\mathrm{H}$ bond in $\mathrm{CH}_{4}$ faces stepped energy barriers toward ${ }^{\star} \mathrm{CH}_{2}$ on $\mathrm{Rh} / \mathrm{CeO}_{2} \mathrm{NWs}$, indicating a much lower selectivity of oxygenates. The formation of $\mathrm{CH}_{3} \mathrm{OOH}$ induced by the. $\mathrm{OOH}$ radical requires an energy cost of $0.47 \mathrm{eV}$, while the generation of $\mathrm{CH}_{3} \mathrm{OH}$ is energetically favorable. Notably, both ${ }^{\star} \mathrm{CH}_{2}$ and $\mathrm{CH}_{3} \mathrm{OOH}$ exhibit an evident energy drop toward the formation of $\mathrm{HCOOH}$, indicating that the overoxidation of $\mathrm{CH}_{4}$ is preferred. However, the further oxidation of $\mathrm{HCOOH}$ to $\mathrm{CO}$ shows an energy barrier of $2.08 \mathrm{eV}$, which further lowers the DMC efficiency. The overall energy release is $1.92 \mathrm{eV}$, which is much smaller than that of SAs Rh- $\mathrm{CeO}_{2} \mathrm{NWs}$, supporting the stronger reaction activity of $\mathrm{SAs} \mathrm{Rh}-\mathrm{CeO}_{2} \mathrm{NWs}$ toward the DMC conversion (Fig. 4i).

Reaction pathways. Combining the results from EPR, in situ DRIFTS and DFT calculations, we thus summarized the reaction paths of DMC on the SAs Rh- $\mathrm{CeO}_{2} \mathrm{NWs}$ and $\mathrm{Rh} / \mathrm{CeO}_{2} \mathrm{NWs}$ (Supplementary Figs. 13 and 14). As displayed in Supplementary Fig. 13, for the SAs Rh-CeO $\mathrm{NWs}_{2} \mathrm{H}_{2} \mathrm{O}_{2}$ can decompose into . $\mathrm{OH}$ on two neighboring $\mathrm{Ce}$ (III) atoms (step 1). On the other hand, $\mathrm{H}_{2} \mathrm{O}_{2}$ can decompose into $\cdot \mathrm{OOH}$ on $\mathrm{Ce}$ (IV), and the remaining $\cdot \mathrm{H}$ will combine with $[\mathrm{O}]$ (lattice $\mathrm{O}$ of $\mathrm{CeO}_{2}$ ) connected with the $\mathrm{Ce}$ (IV) in $\mathrm{CeO}_{2}$ NWs to form $\cdot[\mathrm{O}] \mathrm{H}$ (step 2). The adsorbed $\mathrm{CH}_{4}$ on Rh SA can be oxidized into $\cdot \mathrm{CH}_{3}$ and $\mathrm{H}_{2} \mathrm{O}$ with the assistance of $\cdot \mathrm{OH}$ (step 3). As a result, the formed $\cdot \mathrm{CH}_{3}$ will react with the $\cdot \mathrm{OOH}$ and $\cdot[\mathrm{O}] \mathrm{H}$ radicals to produce $\mathrm{CH}_{3} \mathrm{OOH}$ and $\mathrm{CH}_{3}[\mathrm{O}] \mathrm{H}$ via steps 4 and 5 . It should be noted that the lattice [O] in $\mathrm{CeO}_{2} \mathrm{NWs}$ will be compensated by $\mathrm{H}_{2} \mathrm{O}_{2}(\mathrm{Ce}$ $($ III $) \rightarrow \mathrm{Ce}$ (IV)). By contrast, the reaction paths are different on the $\mathrm{Rh} / \mathrm{CeO}_{2} \mathrm{NWs}$, despite the paths of $\mathrm{H}_{2} \mathrm{O}_{2}$ decomposition (steps 1-2) are the same (Supplementary Fig. 14). On Ru clusters, $\mathrm{CH}_{4}$ can be activated into $\cdot \mathrm{CH}_{3}$ by $\cdot \mathrm{OH}$, which may (i) react with . $[\mathrm{O}] \mathrm{H}$ to $\mathrm{CH}_{3}[\mathrm{O}] \mathrm{H}$ (step 4), or (ii) combine with $\cdot \mathrm{OOH}$ to produce $\mathrm{CH}_{3} \mathrm{OOH}$ (step 5), or (iii) be further oxidized into ${ }^{*} \mathrm{CH}_{2}$ by . $\mathrm{OH}$ (step 6). Both the $\mathrm{CH}_{3} \mathrm{OOH}$ and ${ }^{\star} \mathrm{CH}_{2}$ will be converted into ${ }^{*} \mathrm{CH}_{2} \mathrm{O}$ (steps 7 and 8) and then to ${ }^{*} \mathrm{HCOOH}$ on the $\mathrm{Rh} / \mathrm{CeO}_{2}$ 

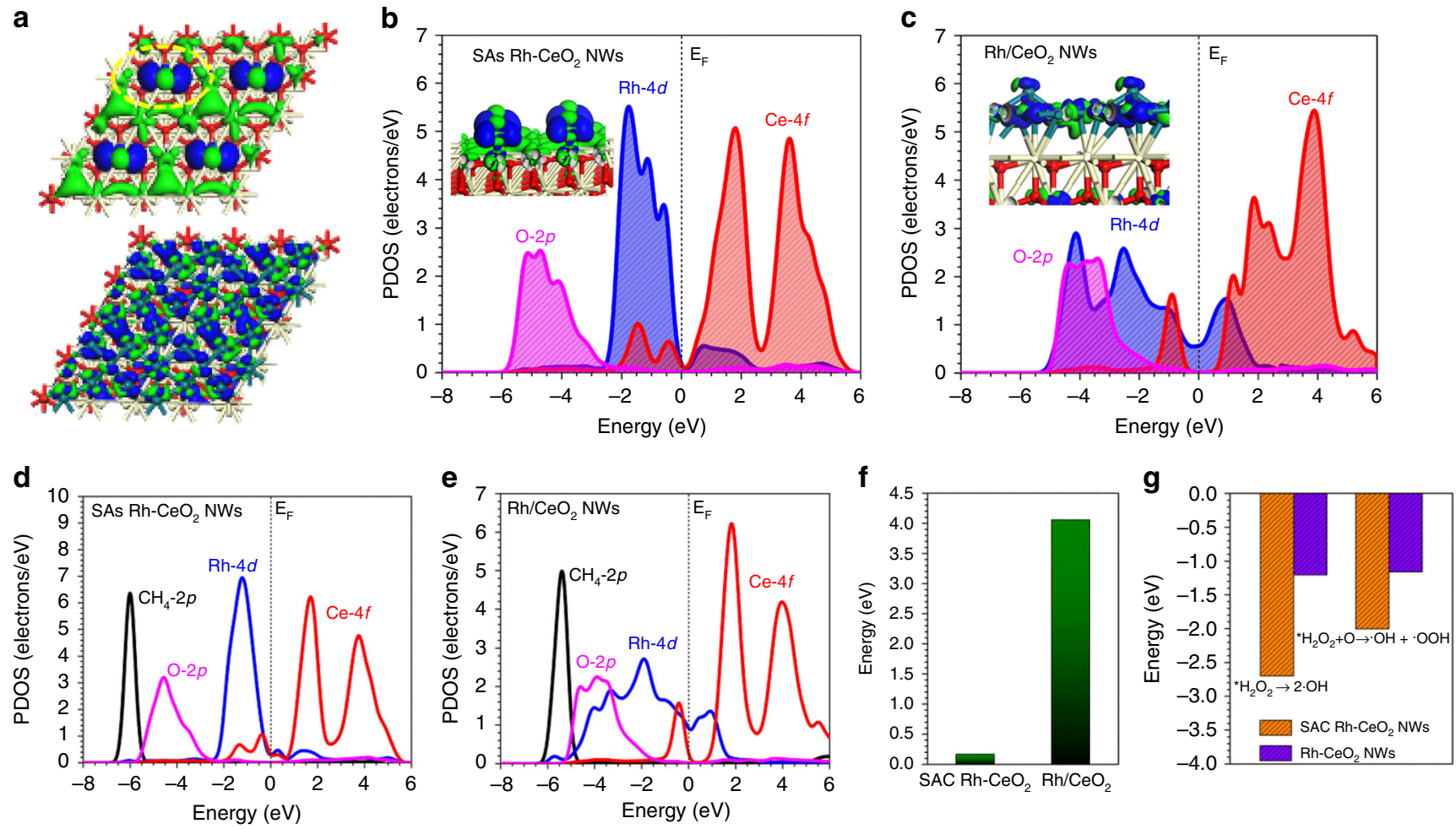

h

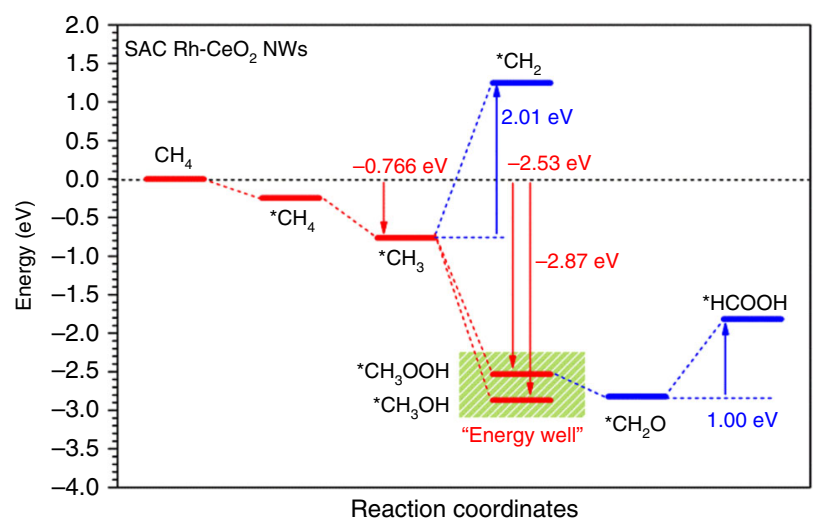

i

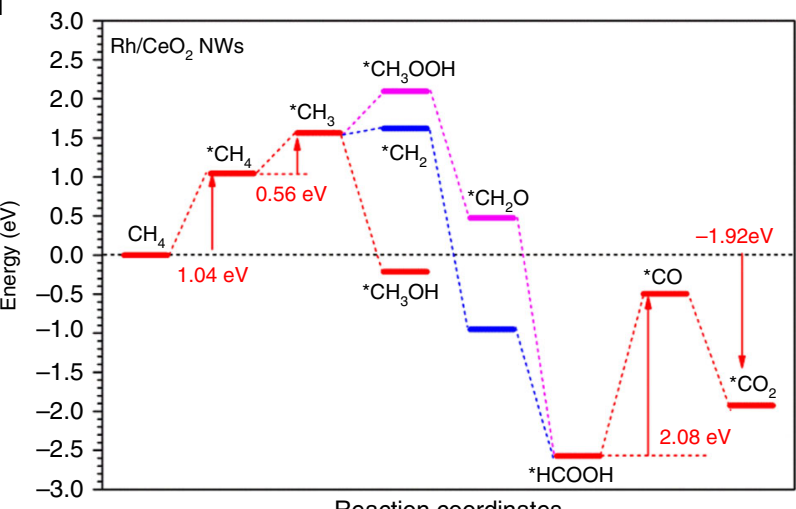

Fig. 4 DFT calculations of DMC reaction paths on $\mathbf{S A s} \mathbf{R h}-\mathbf{C e O}_{\mathbf{2}} \mathbf{N W s}$ and $\mathbf{R h} / \mathbf{C e O}_{\mathbf{2}} \mathbf{N W s}$. a The real spatial contour plots for bonding and antibonding orbitals near $\mathrm{E}_{\mathrm{F}}$ for $\mathrm{SAs} \mathrm{Rh}-\mathrm{CeO}_{2} \mathrm{NWs}$ and $\mathrm{Rh} / \mathrm{CeO}_{2} \mathrm{NWs}$. b The PDOS of SAs Rh- $\mathrm{CeO}_{2} \mathrm{NWs}$ surface. $\mathbf{c}$ The PDOS of Rh/CeO 2 NWs surface. d The PDOS of $\mathrm{CH}_{4}$ adsorption on $\mathrm{SAs} \mathrm{Rh}-\mathrm{CeO}_{2} \mathrm{NWs}$ surface. e The PDOS of $\mathrm{CH}_{4}$ adsorption on $\mathrm{Rh} / \mathrm{CeO}_{2} \mathrm{NWs}$ surface. $\mathbf{f}$ Energy comparison of [O] desorption from $\mathrm{CeO}_{2}$ on $\mathrm{SAs} \mathrm{Rh}-\mathrm{CeO}_{2} \mathrm{NWs}$ and $\mathrm{Rh} / \mathrm{CeO}_{2} \mathrm{NWs}$. $\mathbf{g}$ The reaction energy comparison of generating radicals. $\mathbf{h}$ Reaction paths and energy profile of DMC over SAs Rh- $\mathrm{CeO}_{2} \mathrm{NWs}$. i Reaction paths and energy profile of DMC over the $\mathrm{Rh} / \mathrm{CeO}_{2} \mathrm{NWs}$.

NWs (step 9). Finally, $\mathrm{HCOOH}$ will be further oxidized into $\mathrm{CO}_{\mathrm{x}}$ in the presence of $\cdot \mathrm{OH}$ (steps 10-11).

\section{Discussion}

In summary, we demonstrated that $\mathrm{SAs} \mathrm{Rh}-\mathrm{CeO}_{2} \mathrm{NWs}$ can be used for DMC to oxygenates. Compared with the low selectivity $(56.4 \%)$ and yield $\left(189.4 \mathrm{mmol} \mathrm{g}_{\mathrm{Rh}}{ }^{-1} \mathrm{~h}^{-1}\right)$ of oxygenates from $\mathrm{Rh} / \mathrm{CeO}_{2} \mathrm{NWs}$, the selectivity and yield of $\mathrm{CH}_{3} \mathrm{OH}$ and $\mathrm{CH}_{3} \mathrm{OOH}$ are $93.9 \%$ and $1231.7 \mathrm{mmol} \mathrm{g}_{\mathrm{Rh}}{ }^{-1} \mathrm{~h}^{-1}$ on SAs $\mathrm{Rh}-\mathrm{CeO}_{2} \mathrm{NWs}$ at $50{ }^{\circ} \mathrm{C}$, which to the best of our knowledge outperforms the reported values in the literatures. In situ characterizations and experiments were performed to study the mechanism. It is shown that $\mathrm{CeO}_{2}$ NWs play a vital role in the generation of $\cdot \mathrm{OH}$ and OOH radicals, which can significantly promote the oxidation of $\mathrm{CH}_{4}$ via different reaction paths. To be more specific, SAs Rh$\mathrm{CeO}_{2} \mathrm{NWs}$ can selectively activate $\mathrm{CH}_{4}$ to ${ }^{*} \mathrm{CH}_{3}$, leading to the formation of oxygenate in the presence of $\mathrm{H}_{2} \mathrm{O}_{2}$, while $\mathrm{Rh} / \mathrm{CeO}_{2}$ NWs favor the overoxidation of $\mathrm{CH}_{4}$ to form $\mathrm{CO}_{\mathrm{x}}$, leading to a low selectivity and yield of oxygenates. DFT calculations reveal the facile $\mathrm{C}-\mathrm{H}$ bond activation and reaction locking on SAs Rh$\mathrm{CeO}_{2}$ NWs guarantees the high selectivity and yield of DMC, supplying solid evidence for experimental results. This work may not only provide a highly active and selective catalyst for DMC to oxygenate but also promote the researches of SACs in heterogeneous catalysis.

\section{Methods}

Preparation of $\mathrm{CeO}_{2}$ nanowires (NWs) and $\mathbf{S A s} \mathbf{R h}-\mathrm{CeO}_{\mathbf{2}} \mathbf{N W s}$. In a typical preparation of $\mathrm{CeO}_{2} \mathrm{NWs}, 12 \mathrm{~mL} \mathrm{CeCl}_{3}(0.5 \mathrm{mmol}$, Alfa Aesar $)$ and sodium oleate $(0.75 \mathrm{mmol}$, Tokyo Chemical Industry) aqueous solution were added into a $20-\mathrm{mL}$ Teflon-lined stainless-steel autoclave. The mixture was magnetically stirred at 800 rpm (round per minute) for $0.5 \mathrm{~h}$. To this solution, $n$-butylamine $(1 \mathrm{~mL}$, Sinopharm) was slowly added into the solution under stirring for another $0.5 \mathrm{~h}$. 
Afterward, the autoclave was heated at $160^{\circ} \mathrm{C}$ for $10 \mathrm{~h}$ before it was cooled to room temperature. The resulting products were collected by centrifugation and washed three times with cyclohexane/acetone mixture, and then dried at room temperature overnight. The powder products were subjected to thermal annealing in an air atmosphere at $400{ }^{\circ} \mathrm{C}$ for $10 \mathrm{~min}$ at a heating rate of $10^{\circ} \mathrm{C} \mathrm{min}-1$. For SAs Rh$\mathrm{CeO}_{2} \mathrm{NWs}$, all the parameters were the same with $\mathrm{CeO}_{2} \mathrm{NWs}$, except for adding extra $\mathrm{Na}_{3} \mathrm{RhCl}_{6}(5 \mu \mathrm{mol}$, Aldrich).

Preparation of $\mathbf{R h} / \mathrm{CeO}_{\mathbf{2}} \mathbf{N W s}$ and $\mathbf{R h} / \mathrm{CeO}_{\mathbf{2}}$-com. The $\mathrm{Rh} / \mathrm{CeO}_{2}$ NWs and $\mathrm{Rh} /$ $\mathrm{CeO}_{2}$-com were prepared via a conventional wet-impregnation method. Typically, a certain amount of $\mathrm{Na}_{3} \mathrm{RhCl}_{6}$ solution was dropwise added into the as-prepared $\mathrm{CeO}_{2} \mathrm{NWs}$ and commercial $\mathrm{CeO}_{2}(99.9 \%$, Inoke) under moderate stirring. The resultant slurry was mixed evenly and then dried in an oven at $80{ }^{\circ} \mathrm{C}$ overnight, and then subjected to thermal annealing in air at $400{ }^{\circ} \mathrm{C}$ for $10 \mathrm{~min}$ at a heating rate of $10^{\circ} \mathrm{C} \mathrm{min}^{-1}$. Finally, the calcinated samples were re-washed water for three times via centrifugation, and then dried at $100^{\circ} \mathrm{C}$ overnight.

Characterization. The morphologies and sizes of the NWs were determined by TEM (Hitachi, HT7700) at $120 \mathrm{kV}$. AC-HAADF-STEM images were taken on JEM-ARM200F with a cold-field emission gun and a spherical aberration corrector. The $\mathrm{Rh}$ loading amounts were determined by the inductively coupled plasma atomic emission spectroscopy (ICP-AES) (710-ES, Varian). XRD patterns were collected on X'Pert-Pro MPD diffractometer (Netherlands PANalytical) with a $\mathrm{Cu}$ Ka X-ray source $(\lambda=1.540598 \AA$ ). XPS was done with an SSI S-Probe XPS Spectrometer. The carbon peak at $284.6 \mathrm{eV}$ was used as a reference to correct for charging effects. The X-ray absorption data at the Rh K-edge of the samples were recorded at room temperature in transmission mode using ion chambers at beamline BL14W1 of the Shanghai Synchrotron Radiation Facility (SSRF), China. The station was operated with a Si (311) double-crystal monochromator. During the measurement, the synchrotron was operated at energy of $3.5 \mathrm{GeV}$ and a current between 150 and $210 \mathrm{~mA}$. The photon energy was calibrated with the first inflection point of $\mathrm{Rh} \mathrm{K}$-edge in $\mathrm{Rh}$ metal foil.

Typical process for selective oxidation of $\mathbf{C H}_{\mathbf{4}}$. The selective oxidation of $\mathrm{CH}_{4}$ was performed in a 60 -mL stainless-steel autoclave. Typically, $20 \mathrm{~mL} \mathrm{H}_{2} \mathrm{O}_{2}$ solution $(1 \mathrm{M})$ and $10 \mathrm{mg}$ of catalyst were added into a Teflon inlet. Afterward, the autoclave was pressurized with $\mathrm{CH}_{4}(0.5 \mathrm{MPa})$. The reaction was performed at $50^{\circ} \mathrm{C}$ with stirring at $800 \mathrm{rpm}$ for $1 \mathrm{~h}$. In our work, we used a commercial Agilent GC integrated system with a flame ionization detector (FID) for the detection of gaseous products. This system contains three columns (two hayesep Q columns and one $5 \mathrm{~A} \mathrm{~mol}$ sieve column) for the separation of gaseous products. Both $\mathrm{CO}$ and $\mathrm{CO}_{2}$ were converted into $\mathrm{CH}_{4}$ via a methanator to analyze by FID. All the gaseous products were introduced into two tandem hayesep $\mathrm{Q}$ columns for pre-separation. $\mathrm{CO}_{2}$ was completely separated in this process and introduced into the FID via a switch valve. The remaining gases were further introduced into a $5 \mathrm{~A}$ mol sieve column for further separation. ${ }^{1} \mathrm{H}$ nuclear magnetic resonance spectroscopy $\left({ }^{1} \mathrm{H}-\right.$ NMR, Bruker $600 \mathrm{MHz}$ ) was employed for structural analysis of liquid products, in which dimethylsulfoxide (DMSO, 1\%o) and deuteroxide were used as the internal standard and solvent, respectively. The liquid products were analyzed by a gas chromatograph (Persee G5) with a FID using a KB-5 column. In total, $10 \mu \mathrm{L}$ of isopropanol/ $/ \mathrm{H}_{2} \mathrm{O}(1 \%)$ was used as the internal standard adding into $1 \mathrm{~mL}$ reaction mixture for analyzing $\mathrm{CH}_{3} \mathrm{OH}$ and $\mathrm{CH}_{3} \mathrm{OOH}$. The amount of $\mathrm{CH}_{3} \mathrm{OH}$ was calculated using the standard curve method. Afterward, $\mathrm{CH}_{3} \mathrm{OOH}$ was converted to $\mathrm{CH}_{3} \mathrm{OH}$ using hydrazine hydrate $(0.1 \mathrm{~mL})$. The total amount of $\mathrm{CH}_{3} \mathrm{OH}$ and $\mathrm{CH}_{3} \mathrm{OOH}$ were analyzed by gas chromatograph, and the amount of $\mathrm{CH}_{3} \mathrm{OOH}$ was obtained by minusing. For each catalytic test, error bar was obtained by repeating three times. The yields of products and the selectivity were calculated using Eqs. (1) and (2).

Yields of products $\left(\mathrm{mmol} \mathrm{g}_{\mathrm{Rh}}^{-1} \mathrm{~h}^{-1}\right)=\mathrm{mmol}$ of products $/ \mathrm{g}$ of $\mathrm{Rh} / \mathrm{h}$ of reaction time

Oxygenates selectivity $(\%)=\operatorname{mmol}$ of $\left(\mathrm{CH}_{3} \mathrm{OOH}+\mathrm{CH}_{3} \mathrm{OH}\right)$ $\times 100 / \mathrm{mmol}$ of all products

EPR measurement. The detection of free radicals in the reaction process of DMC was performed at a JEOL JES-FA200 electron paramagnetic resonance spectroscopy (EPR, $9.062 \mathrm{GHz}$ ), using DMPO as the scavenger. Typically, $1 \mathrm{~mL}$ DMPO$\mathrm{H}_{2} \mathrm{O}\left(100 \mathrm{mmol} \mathrm{L}^{-1}\right)$ was added into $1 \mathrm{~mL}$ of reaction mixture. The mixed solution was immediately transferred to a capillary tube (diameter: $0.1 \mathrm{~mm}$; filling liquid height: $\sim 5 \mathrm{~cm}$ ), which was then fixed in the resonant cavity of the spectrometer. EPR measurements were detected at room temperature and recorded by three scans. The contrast experiments were performed to determine the type of radicals by characteristic peaks. Contrast experiment 1 (labeled as DMPO $+\mathrm{H}_{2} \mathrm{O}_{2}+\mathrm{Fe}^{2+}$ ): $1 \mathrm{~mL}$ ferrous (II) sulfate $\left(\mathrm{FeSO}_{4}, 50 \mathrm{mmol} \mathrm{L}^{-1}\right)$ and nitric acid solution $(\mathrm{pH}=4)$ were mixed with $1 \mathrm{~mL}$ DMPO- $\mathrm{H}_{2} \mathrm{O}\left(100 \mathrm{mmol} \mathrm{L}^{-1}\right)$ under moderate stirring for $2 \mathrm{~min}$, followed by adding $50 \mu \mathrm{L}$ of $\mathrm{H}_{2} \mathrm{O}_{2}$ (30 wt.\%). Contrast experiment 2 (labeled as $\left.\mathrm{DMPO}+\mathrm{H}_{2} \mathrm{O}_{2}+\mathrm{Fe}^{2+}+\mathrm{CH}_{3} \mathrm{OH}\right)$ : all the processes were the same with contrast experiment 1 , except for the addition of $1 \mathrm{~mL}$ of $\mathrm{CH}_{3} \mathrm{OH}\left(100 \mathrm{mmol} \mathrm{L}^{-1}\right)$ into the solution.

CO-DRIFTS measurement. In all, $20 \mathrm{mg}$ sample was packed into a Harrick Praying Mantis high-temperature reaction chamber $\left(\mathrm{CaF}_{2}\right.$ windows $)$ mounted inside of a Thermo Scientific Praying Mantis diffuse reflectance adapter, set inside of a Thermo Scientific Nicolet 6700 Fourier transform infrared (FT-IR) spectrometer using liquid nitrogen cooled mercury-cadmium-telluride detector (MCT). Gases were flowed to the reaction chamber using Alicat mass flow controllers. Prior to CO-DRIFTS measurement, the sample was pretreated by heating in $\mathrm{CO} / \mathrm{Ar}$ (10 vol.\%) flow $\left(50 \mathrm{~mL} \mathrm{~min}^{-1}\right)$ at different temperatures (e.g., $-30^{\circ} \mathrm{C}, 50^{\circ} \mathrm{C}$, and $150^{\circ} \mathrm{C}$ ), followed by flushing with Ar flow $\left(50 \mathrm{~mL} \mathrm{~min}^{-1}\right)$ for $1 \mathrm{~h}$. After cooling to $-30^{\circ} \mathrm{C}$ in the same $\mathrm{Ar}$ flow, $\mathrm{CO} / \mathrm{Ar}\left(10 \mathrm{vol} . \%, 50 \mathrm{~mL} \mathrm{~min}^{-1}\right)$ was flowed through the sample at $-30^{\circ} \mathrm{C}$ for $0.5 \mathrm{~h}$. Finally, the sample was flushed with Ar flow $\left(50 \mathrm{~mL} \mathrm{~min}^{-1}\right)$ at $-30^{\circ} \mathrm{C}$ for $0.5 \mathrm{~h}$ to remove the physically adsorbed $\mathrm{CO}$ on the surface sample. The CO-DRIFTS spectra were obtained by averaging 16 sequentially collected scans at a resolution of $4 \mathrm{~cm}^{-1}$.

In situ $\mathrm{CH}_{4}$-DRIFTS measurement. For in situ $\mathrm{CH}_{4}$-DRIFT, $20 \mathrm{mg}$ sample was packed into a Harrick Praying Mantis high-temperature reaction chamber $\left(\mathrm{CaF}_{2}\right.$ windows) mounted inside of a Thermo Scientific Praying Mantis diffuse reflectance adapter, set inside of a Thermo Scientific Nicolet 6700 FT-IR spectrometer using liquid nitrogen cooled MCT detector. The sample was pretreated by heating in $\mathrm{Ar}$ flow $\left(50 \mathrm{~mL} \mathrm{~min}^{-1}\right)$ at $400{ }^{\circ} \mathrm{C}$ for $1 \mathrm{~h}$ and cooled down to $50^{\circ} \mathrm{C}$ in the same Ar flow. Gases ( 5 vol.\% $\mathrm{CH}_{4} / \mathrm{Ar}$ or $\mathrm{Ar}$ ) were flowed using Alicat mass flow controllers. The hydrogen peroxide is brought into the chamber by a carrier gas $\left(5\right.$ vol.\% $\left.\mathrm{CH}_{4} / \mathrm{Ar}\right)$ with a positive pressure $(0.15 \mathrm{MPa})$. Afterward, $5 \mathrm{vol} . \% \mathrm{CH}_{4} / \mathrm{Ar}$ with the hydrogen peroxide was flowed through the catalyst bed at $50^{\circ} \mathrm{C}$ for $0.5 \mathrm{~h}$, followed by flushing with Ar flow $\left(50 \mathrm{~mL} \mathrm{~min}^{-1}\right)$ for $0.5 \mathrm{~h}$ at the same temperature. The in situ $\mathrm{CH}_{4}{ }^{-}$ DRIFTS spectra were obtained by averaging 16 sequentially collected scans at a resolution of $4 \mathrm{~cm}^{-1}$. For $\mathrm{CH}_{4}$-DRIFTS measurement, all the parameters are the same with in situ $\mathrm{CH}_{4}$-DRIFTS measurement, except for the absence of $\mathrm{H}_{2} \mathrm{O}_{2}$.

DFT calculations. All calculations were carried out using DFT implemented in the CASTEP $^{36}$. The electron exchange and correlation interaction were calculated with the generalized gradient approximation (GGA) in the parametrization of Perdew-Burke-Ernzerhof (PBE) pseudopotentials ${ }^{37,38}$. To minimize the computational cost for the surface modeling, ultrasoft pseudopotential scheme has been chosen with the cutoff energy of $410 \mathrm{eV}^{39,40}$. For both SAs Rh- $\mathrm{CeO}_{2}$ and $\mathrm{Rh} / \mathrm{CeO}_{2}$, the $\mathrm{CeO}_{2}$ crystal has been cleaved along the (111) plane with three-layer thickness. For SAs Rh- $-\mathrm{CeO}_{2}$ model, only one $\mathrm{Rh}$ atom is deposited onto the $\mathrm{CeO}_{2}$ surface within the unit cell to demonstrate the single-atom catalyst. For $\mathrm{Rh} / \mathrm{CeO}_{2} \mathrm{NWs}$ model, the Rh cluster consists of eight atoms, which is cleaved from the bulk $\mathrm{Rh}$ crystal along the (111) plane. We imposed a $15 \AA$ vacuum space along $z$-direction to supply sufficient space for the adsorption behaviors without interactions between lattice. For all the geometry optimizations, the Hellmann-Feynman forces will be converged to $<0.001 \mathrm{eV} / \mathrm{A}$, while the total energy has been converged to $5 \times$ $10^{-5} \mathrm{eV}$ per atom. The coarse k-point has been applied for the energy minimization based on the Broyden-Fletcher-Goldfarb-Shannon (BFGS) algorithm ${ }^{41,42}$.

\section{Data availability}

The data supporting this study are available in the paper and Supplementary Information. All other relevant source data are available from the corresponding authors upon reasonable request.

Received: 17 September 2019; Accepted: 15 December 2019; Published online: 19 February 2020

\section{References}

1. Wang, V. C. C. et al. Alkane oxidation: methane monooxygenases, related enzymes, and their biomimetics. Chem. Rev. 117, 8574-8621 (2017).

2. Shan, J. et al. Mild oxidation of methane to methanol or acetic acid on supported isolated rhodium catalysts. Nature 551, 605-608 (2017).

3. Hickman, D. A. \& Schmidt, L. D. Production of syngas by direct catalytic oxidation of methane. Science 259, 343-346 (1993).

4. Schwach, P., Pan, X. \& Bao, X. Direct conversion of methane to value-added chemicals over heterogeneous catalysts: challenges and prospects. Chem. Rev. 117, 8497-8520 (2017).

5. Liang, Z. et al. Low-temperature activation of methane on the $\mathrm{IrO}_{2}(110)$ surface. Science 356, 299-303 (2017).

6. Ravi, M., Ranocchiari, M. \& van Bokhoven, J. A. The direct catalytic oxidation of methane to methanol-a critical assessment. Angew. Chem. Int. Ed. 56, 16464-16483 (2017) 
7. Spivey, J. J. \& Hutchings, G. Catalytic aromatization of methane. Chem. Soc. Rev. 43, 792-803 (2014).

8. Periana, R. A. et al. Platinum catalysts for the high-yield oxidation of methane to a methanol derivative. Science 280, 560-564 (1998).

9. Sushkevich, V. L., Palagin, D. \& van Bokhoven, J. A. The effect of the activesite structure on the activity of copper mordenite in the aerobic and anaerobic conversion of methane into methanol. Angew. Chem. Int. Ed. 57, 8906-8910 (2018).

10. Agarwal, N. et al. Aqueous Au-Pd colloids catalyze selective $\mathrm{CH}_{4}$ oxidation to $\mathrm{CH}_{3} \mathrm{OH}$ with $\mathrm{O}_{2}$ under mild conditions. Science 358, 223-227 (2017).

11. Yang, X. F. et al. Single-atom catalysts: a new frontier in heterogeneous catalysis. Acc. Chem. Res. 46, 1740-1748 (2013).

12. Pelletier, J. D. A. \& Basset, J. M. Catalysis by design: well-defined single-site heterogeneous catalysts. Acc. Chem. Res. 49, 664-677 (2016).

13. Valden, M., Lai, X. \& Goodman, D. W. O. Onset of catalytic activity of gold clusters on titania with the appearance of nonmetallic properties. Science 281, $1647-1650$ (1998).

14. Huang, W. X. et al. Low-temperature transformation of methane to methanol on $\mathrm{Pd}_{1} \mathrm{O}_{4}$ single sites anchored on the internal surface of microporous silicate. Angew. Chem. Int. Ed. 55, 13441-13445 (2016).

15. Tang, Y. et al. Single rhodium atoms anchored in micropores for efficient transformation of methane under mild conditions. Nat. Commun. 9, 1231 (2018).

16. Kwon, Y. et al. Selective activation of methane on single-atom catalyst of rhodium dispersed on zirconia for direct conversion. J. Am. Chem. Soc. 139, 17694-17699 (2017).

17. Kyriakou, G. et al. Isolated metal atom geometries as a strategy for selective heterogeneous hydrogenations. Science 335, 1209-1212 (2012).

18. Yan, H. et al. Single-atom $\mathrm{Pd}_{1} /$ graphene catalyst achieved by atomic layer deposition: remarkable performance in selective hydrogenation of $1,3-$ butadiene. J. Am. Chem. Soc. 137, 10484-10487 (2015).

19. Pei, G. X. et al. Ag alloyed Pd single-atom catalysts for efficient selective hydrogenation of acetylene to ethylene in excess ethylene. ACS Catal. 5, 3717-3725 (2015).

20. Lucci, F. R. et al. Selective hydrogenation of 1, 3-butadiene on platinumcopper alloys at the single-atom limit. Nat. Commun. 6, 8550 (2015).

21. Kim, M. \& Laine, R. M. One-step synthesis of core-shell $\left(\mathrm{Ce}_{0.7} \mathrm{Zr}_{0.3} \mathrm{O}_{2}\right)_{\mathrm{x}}\left(\mathrm{Al}_{2} \mathrm{O}_{3}\right)_{1}-_{\mathrm{x}}\left[\left(\mathrm{Ce}_{0.7} \mathrm{Zr}_{0.3} \mathrm{O}_{2}\right) @ \mathrm{Al}_{2} \mathrm{O}_{3}\right]$ nanopowders via liquid-feed flame spray pyrolysis (LF-FSP). J. Am. Chem. Soc. 131, 9220-9229 (2009).

22. Liu, X. et al. Oxygen vacancy clusters promoting reducibility and activity of ceria nanorods. J. Am. Chem. Soc. 131, 3140-3141 (2009).

23. Wang, L. et al. Atomic-level insights in optimizing reaction paths for hydroformylation reaction over $\mathrm{Rh} / \mathrm{CoO}$ single-atom catalyst. Nat. Commun. 7, 14036 (2016).

24. Rice, C. A. et al. The oxidation state of dispersed $\mathrm{Rh}^{\circ} \mathrm{Al}_{2} \mathrm{O}_{3}$. J. Chem. Phys. 74, 6487-6497 (1981).

25. Lang, R. et al. Hydroformylation of olefins by a rhodium single-atom catalyst with activity comparable to $\mathrm{RhCl}\left(\mathrm{PPh}_{3}\right)_{3}$. Angew. Chem. Int. Ed. 55, 16054-16058 (2016).

26. Hammond, C. et al. Direct catalytic conversion of methane to methanol in an aqueous medium by using copper-promoted Fe-ZSM-5. Angew. Chem. Int. Ed. 51, 5129-5133 (2012).

27. Rosen, G. M. et al. Influence of conformation on the EPR spectrum of 5,5dimethyl-1-hydroperoxy-1-pyrrolidinyloxyl: a spin trapped adduct of superoxide. J. Org. Chem. 69, 1321-1330 (2004).

28. Engdahla, A. \& Nelander, B. The $\mathrm{HOOH}-\mathrm{HOO}$ complex. A matrix isolation study. Phys. Chem. Chem. Phys. 6, 730-734 (2004).

29. Cai, W. et al. Enhanced catalytic degradation of $\mathrm{AO}_{7}$ in the $\mathrm{CeO}_{2}-\mathrm{H}_{2} \mathrm{O}_{2}$ system with $\mathrm{Fe}^{3+}$ doping. Appl. Catal. B: Environ. 101, 160-168 (2010).

30. Ji, P. et al. $\mathrm{Ce}^{3+}$-centric organic pollutant elimination by $\mathrm{CeO}_{2}$ in the presence of $\mathrm{H}_{2} \mathrm{O}_{2}$. ChemCatChem 2, 1552-1554 (2010).

31. Wang, Y. \& Wöll, C. IR spectroscopic investigations of chemical and photochemical reactions on metal oxides: bridging the materials gap. Chem. Soc. Rev. 46, 1875-1932 (2017).

32. $\mathrm{Wu}, \mathrm{Z}$. et al. Probing the surface sites of $\mathrm{CeO}_{2}$ nanocrystals with well-defined surface planes via methanol adsorption and desorption. ACS Catal. 2, 2224-2234 (2012).

33. Liu, B. et al. Oxygen vacancy promoting dimethyl carbonate synthesis from $\mathrm{CO}_{2}$ and methanol over $\mathrm{Zr}$-doped $\mathrm{CeO}_{2}$ nanorods. ACS Catal. 8, 10446-10456 (2018).

34. Newton, M. A. et al. Room-temperature carbon monoxide oxidation by oxygen over $\mathrm{Pt} / \mathrm{Al}_{2} \mathrm{O}_{3}$ mediated by reactive platinum carbonates. Nat. Commun. 6, 8675 (2015).
35. Graciani, J. et al. Highly active copper-ceria and copper-ceria-titania catalysts for methanol synthesis from $\mathrm{CO}_{2}$. Science 345, 546-550 (2014).

36. Clark, S. J. et al. First principles methods using CASTEP. Z. Fur Kristallographie 220, 567-570 (2005).

37. Perdew, J. P., Burke, K. \& Ernzerhof, M. Generalized gradient approximation made simple. Phys. Rev. Lett. 77, 3865-3868 (1996).

38. Hasnip, P. J. \& Pickard, C. J. Electronic energy minimisation with ultrasoft pseudopotentials. Comput. Phys. Commun. 174, 24-29 (2006).

39. Vanderbilt, D. Soft self-consistent pseudopotentials in a generalized eigenvalue formalism. Phys. Rev. B 41, 7892-7895 (1990).

40. Perdew, J. P. et al. Atoms, molecules, solids, and surfaces: applications of the generalized gradient approximation for exchange and correlation. Phys. Rev. B 46, 6671-6687 (1992).

41. Head, J. D. \& Zerner, M. C. A Broyden-Fletcher-Goldfarb-Shanno optimization procedure for molecular geometries. Chem. Phys. Lett. 122, 264-270 (1985).

42. Probert, M. I. J. \& Payne, M. C. Improving the convergence of defect calculations in supercells: anab initio study of the neutral silicon vacancy. Phys. Rev. B 67, 075204 (2003).

\section{Acknowledgements}

This work was financially supported by the Ministry of Science and Technology (2016YFA0204100, 2017YFA0208200), the National Natural Science Foundation of China (21571135), Young Thousand Talented Program, Jiangsu Province Natural Science Fund for Distinguished Young Scholars (BK20170003), the project of scientific and technologic infrastructure of Suzhou (SZS201708), the Priority Academic Program Development of Jiangsu Higher Education Institutions (PAPD), and the start-up supports from Soochow University. The authors thank beamline BL14W1 (Shanghai Synchrotron Radiation Facility) for providing the beam time.

\section{Author contributions}

X.H. and Y.X. conceived and supervised the research. X.H., S.B., and Y.X. designed the experiments. X.H., S.B., Y.X., and Q.S. performed most of the experiments and data analysis. J.W. and Fan Li performed and analyzed the STEM characterization. X.H., S.B. Y.X., Q.S., Fangfang Liu, and H.L. participated in various aspects of the experiments and discussions. Fangfang Liu, B.H., H.L., T.W., and M.S. performed the DFT simulations. X.H., S.B., and Y.X. wrote the paper. All authors discussed the results and commented on the paper.

\section{Competing interests}

The authors declare no competing interests.

\section{Additional information}

Supplementary information is available for this paper at https://doi.org/10.1038/s41467 020-14742-x.

Correspondence and requests for materials should be addressed to J.W., Y.X. or X.H.

Peer review information Nature Communications thanks the anonymous reviewer(s) for their contribution to the peer review of this work.

Reprints and permission information is available at http://www.nature.com/reprints

Publisher's note Springer Nature remains neutral with regard to jurisdictional claims in published maps and institutional affiliations.

Open Access This article is licensed under a Creative Commons Attribution 4.0 International License, which permits use, sharing, adaptation, distribution and reproduction in any medium or format, as long as you give appropriate credit to the original author(s) and the source, provide a link to the Creative Commons license, and indicate if changes were made. The images or other third party material in this article are included in the article's Creative Commons license, unless indicated otherwise in a credit line to the material. If material is not included in the article's Creative Commons license and your intended use is not permitted by statutory regulation or exceeds the permitted use, you will need to obtain permission directly from the copyright holder. To view a copy of this license, visit http://creativecommons.org/ licenses/by/4.0/.

(C) The Author(s) 2020 